\title{
Targeted Neocortical Cell Death in Adult Mice Guides Migration and Differentiation of Transplanted Embryonic Neurons
}

\author{
Volney L. Sheen and Jeffrey D. Macklis \\ Department of Neurology and Program in Neuroscience, Harvard Medical School and Mental Retardation Research \\ Center, Department of Neurology, Children's Hospital, Boston, Massachusetts 02115
}

Local expression of cellular and molecular signals is required for normal neuronal migration and differentiation during neocortical development and during periods of plasticity in the adult brain. We have previously shown in neonatal and juvenile mice that induction of apoptotic degeneration in neocortical pyramidal neurons by targeted photolysis provides an altered environment that directs migration and differentiation of transplanted embryonic neurons. Here we employ the same paradigm in adult mice to test whether targeted photolysis induces the reexpression in the mature brain of developmental signals that control migration, differentiation and integration of embryonic neurons. We examined both the time course of migration and the morphologic and immunocytochemical differentiation of embryonic neurons transplanted into regions of targeted photolytic cell death.

Pyramidal neurons in neocortical lamina II/III underwent photolytically induced apoptosis after retrograde incorporation of the photoactive chromophore chlorin $e_{6}$ and transdural exposure to $674 \mathrm{~nm}$ near-infrared laser energy. Embryonic day 17 neocortical neurons were prelabeled with fluorescent nanospheres and the lipophilic dye PKH26, transplanted into regions of ongoing neuronal degeneration in adult mice, and examined histologically and immunocytochemically. Transplanted neurons began migration into regions of neuronal death within $3 \mathbf{d}$ and differentiated into large pyramidal neurons similar to those degenerating. In contrast, neurons transplanted into intact cortex did not migrate, and they differentiate into small presumptive interneurons. Migration up to $\mathbf{4 3 0} \boldsymbol{\mu m}$ in experimental mice was complete by 2 weeks; approximately $45 \%$ of the donor neurons migrated greater than 3 SDs beyond the mean for neurons transplanted into intact neocortex of age-matched adult hosts. Following migration, dendrites and axons of many donor neurons were properly oriented toward the pial surface and corpus callosum, indicating integration into

\footnotetext{
Received July 7, 1995; accepted Aug. 24, 1995.

This work was supported by NIH Grants HD28478 and MR Center Grant HD 18655, the Alzheimer's Association/Samuel A. Blank Investigator-Initiated Research Grant, and the Rita Allen Foundation. V.L.S. was supported by Training Grants NS/2064 and MHI80I2. We thank Liem Iran and I ina Wilusz for excellent technical assistance. We also thank Prof. Barry Nalebuff for helpful discussions regarding statistical analysis, and Drs. Kristen Harris, James Quattrochi, and Evan Snyder, and two anonymous reviewers for comments on the manuscript. V.L.S. is a Leopold Schepp Foundation predoctoral fellow, and J.D.M. is a Rita Allen Foundation Scholar.

Correspondence should be addressed to Jeffrey D. Macklis, Enders 354, 320 Longwood Avenue, Boston, MA 02115.

Copyright (C) 1995 Society for Neuroscience $\quad 0270-6474 / 95 / 158378-15 \$ 05.00 / 0$
}

the host parenchyma. Neurofilament and neuron-specific enolase staining further support appropriate differentiation and integration.

These results indicate that signals guiding neuronal migration and differentiation in neocortex are reexpressed in adult mice well beyond the period of corticogenesis within regions of targeted photolytic cell death. Elucidating the molecular mechanisms underlying these events by comparison withadjacent unperturbed regions will contribute to efforts toward future therapeutic transplantation and control over endogenous plasticity.

[Key words: adult mouse, apoptosis, differentiation, integration, laser, migration, neocortex, neuronal degeneration, targeted photolysis, transplantation]

Control over neuronal migration and differentiation depends in part upon local expression of neuronal, glial, and extracellular signals during development or during periods of plasticity in the adult (Hynes et al., 1986; Hynes et al., 1989; Ghosh et al., 1990; Gao et al., 1991; Ferrari et al., 1993; Fishman and Hatten, 1993; Goodman and Shatz, 1993). In neocortex, neurngenesis is limited to a brief embryonic period, and neuronal migration continues only during the first postnatal week (Angevine and Sidman, 1961; Austin and Cepko, 1990; Bayer and Altman, 1991). Disappearance of a highly ordered temporal and spatial pattern of molecular and activity-dependent signals during maturation is thought to underlie the relative lack of plasticity observed in the mature mammalian CNS. Understanding the signals controlling initial neuronal migration and differentiation during neocortical development may allow future therapeutic manipulation of these regulatory molecules.

Disruption of cell-cell and cell-matrix interactions by selective photolytic degeneration of neocortical pyramidal neurons with callosal projections produces a local environment that regulates the migration and differentiation of cmbryonic neocortical neurons transplanted into the neocortex of neonatal or juvenile host mice (Macklis, 1993). Targeted neuronal death is produced in a controlled, synchronous manner in vivo while maintaining complex three-dimensional relationships between cells. This new microenvironment activates migration by donor neurons into only affected regions in lamina II/III, differentiation to replace the degenerated pyramidal neuroms, formation of anatomically correct axons and dendrites, and ultrastructural integration with afferent synapse formation. These phenomena were not observed with control transplants into intact cortex or cortex lesioned by kainic acid with resultant necrotic and inflammatory neuronal and glial injury. Additional experiments demonstrated the localization of signal alterations to the regions of neuronal 
degencration and that the response to these signals was specific to neocortical neurons and not those from other regions of the CNS. These findings suggest that developmental regulatory signals guiding neuronal migration and differentiation may be upregulated during extremely selective degeneration of a targeted neuronal subpopulation.

Degeneration in vivo can be effected within lamina II/III by targeted photolytic cell death (Macklis, 1993; Madison and Macklis, 1993). We have recently demonstrated that neuronal degeneration initiated following targeted photolysis occurs via apoptosis (Sheen et al., 1992; Sheen and Macklis, 1994). Degeneration results from the photoactivation of retrogradely transported nanospheres containing the chromophore chlorin $\mathrm{e}_{6}$. Chlorin $e_{6}$ produces the cytotoxic molecule singlet oxygen when excited at near-infrared wavelengths; light at these wavelengths (produced by a specific $674 \mathrm{~nm}$ laser and beam controlling optics) penetrates deeply through nervous system tissue without absorption or cellular injury to nontargeted cells. Thus, intermixed neurons, glia, axons, and connective tissue are entirely spared, and only neurons selectively labeled with the chromophore undergo degeneration which is progressive and noninflammatory. Nanospheres containing chlorin $\mathrm{e}_{6}$ are localized to lysosomal granules, and photolytic activation of singlet oxygen leads to lipid peroxidation of lysosomal membranes and release of proteolytic contents. The cell undergoes an internal autolysis by singlet oxygen and proteases, leading to a slowly progressive cell death with a loss of calcium homeostasis through L-type calcium channel activation and an increase in membrane permeability. Disruption of cytoplasmic proteins and cytoskeletal components with preservation of membrane bound organelles is accompanied by the appearance of apoptotic membrane bodies and internucleosomal DNA fragmentation. As with other initiating events leading to apoptosis, these targeted cells degenerate and are phagocytosed in vivo without the inflammation or scar formation observed with necrotic cell death. It is possible that the slow, non-necrotic process of targeted neuronal cell death following photolytic activation of singlet oxygen in vivo produces many of the same physiological cues that are activated by programmed cell death during normal development and during organizational refincment in the adult vertebrate nervous system. The similarity in the mechanisms of cell death may underlie similar compensatory mechanisms resulting from a loss of cellcell and/or cell-matrix interactions.

In the mammalian CNS, plasticity and developmental signals influencing neuronal migration and differentiation are thought to decrease with maturity. The age of the 2 week old host mice used in our prior experiments was chosen to be beyond the period of normal neuronal migration, which ends by $5-10 \mathrm{~d}$ postnatally, but still during a period of relative plasticity observed in juvenile animals. Recent experiments using this transplantation paradigm with a clonal donor population demonstrated that the phenotypic fate of multipotent precursor cells placed into regions of targeted photolytic neuron death is influenced by the alteration of microenvironmental signals such that differentiation into pyramidal neurons occurs in postnatal experimental mice, but no neuronal differentiation occurs in intact mice or mice with nonspecific kainic acid lesions (Macklis et al., 1994; E. Y. Snyder, C. H. Yoon, J. D. Flax, and J. D. Macklis, unpublished observations). Together, these results suggest that developmental signals in the microenvironment have been either upregulated or disinhibited to effect both neuronal migration and directed differentiation. Study of the temporal and spatial patterns of signal alterations within these regions of targeted apoptosis would be most productive within mature hosts in whom normal developmental signal patterns have long disappeared.

The present experiments involve an examination in adult mice of the time course of migration and the differentiation and integration of embryonic day 17 (E17) neurons transplanted through regions of targeted photolytic neuronal degeneration. These experiments evaluate whether the developmentally appropriate events seen in juvenile mice (Macklis, 1993) can occur in mature mice in whom decreased plasticity might be expected, allowing examination of mechanisms underlying neocortical migration and differentiation in vivo. We provide evidence at three levels of analysis that the directed migration and differentiation of transplanted embryonic neurons within regions of targeted photolytic cell death in neocortex also occur in adults. We observed the initiation of cellular migration by $3 \mathrm{~d}$ after transplantation and the repopulation of regions following photolytic degeneration in the adult hosts. Neurons transplanted within regions of neuron deficiency assumed morphologies and immunocytochemical staining characteristic of the previously targeted neocortical pyramidal neurons, often displaying appropriate radially oriented axons and dendrites. 'I'hese findings suggest that signals regulating neocortical development may be reexpressed in a temporally and spatially correct manner within the regions of targeted photolytic cell death in fully adult mice in which most developmentally regulated molecules are normally downregulated.

A preliminary report of some of these experiments has been presented previously (Macklis and Sheen, 1992).

\section{Materials and Methods}

This study is based on data from 156 adult $\mathrm{C} 57 \mathrm{~B} / 6 \mathrm{~J}$ mice. Fifty-nine host mice and 14 separate embryonic dissections were used for studies of neuronal migration and differentiation after transplantation. Each dissection contained cells from six to nine mouse embryos at E17. Sixty mice were used for analysis of neuronal targeting and degeneration in experimental hosts. An additional 37 mice were used to assess neuronal degeneration by silver staining and DNA end terminal labeling following initiation of targeted cell death by noninvasive exposure to laser energy.

The experimental paradigm (Fig. 1a) requires targeting of callosally projecting pyramidal neurons by unilateral injection of fluoroscein latex nanospheres conjugated with chlorin $\mathrm{e}_{6}$ into P1 to P16 host mice. After 2 weeks to allow for retrograde transport of latex nanospheres, neuronal degeneration was initiated in the experimental mice by targeted laser photolysis. Cellular transplantation, using dissociated cell suspensions of embryonic neocortex labeled with rhodamine nanospheres that label neurons relatively selectively (Madison et al., 1990; Macklis, 1993) was performed 2 weeks later in 4 or 6 week old experimental mice and in age-matched intact controls. Targeted neurons undergo a gradual and progressive degeneration extending over several weeks such that neurons in the process of cell death are still present at the time of transplantation within the region of cortex exposed to laser energy. Initial analysis was performed on littermate mice 4-5 d following cortical injection of nanospheres to ensure successful transport to pyramidal neurons in contralateral cortex. One day to 2 weeks following targeted laser photolysis, other mice were analyzed to ensure induction of neuronal degeneration. Experimental mice underwent light microscopic (LM) analysis of serial sections alternately processed for fluorescence and routine histology $3 \mathrm{~d}$ or 1,2, 4, or 6 weeks after transplantation (Macklis, 1993; Madison and Macklis, 1993). The positions of donor neurons were analyzed in experimental mice at $3 \mathrm{~d}(n=4), 1$ week $(n$ $=3), 2$ weeks $(n=14), 4$ weeks $(n=8)$ or 6 weeks $(n=2)$ after transplantation. Morphology and local projections of transplanted neurons, labeled with the lipophilic dye PKH26, were analyzed in experimental mice at 1 week $(n=3)$ and 2 weeks $(n=8)$ after transplantation. Intact control adult hosts underwent $\mathrm{LM}$ analysis by fluorescence and routine histology 1 week $(n=6), 2$ weeks $(n=7), 3$ weeks $(n=$ $2)$, and 4 weeks $(n=4)$ following transplantation of E17 neurons. 


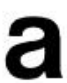

chlorin egnanospheres microinjection and neuronal uptake

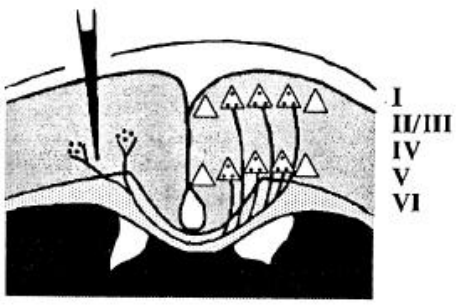

\begin{abstract}
retrograde transport of nanospheres
\end{abstract}
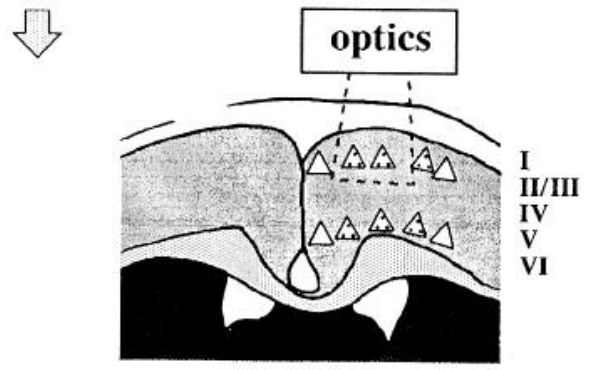

degeneration

\section{transplant of}

embryonic day 17

neocortical neurons

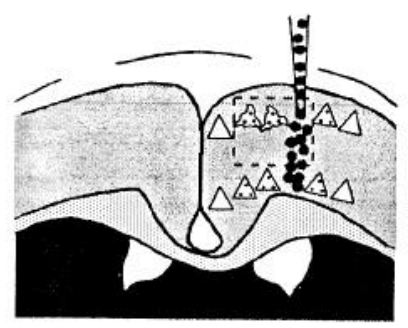

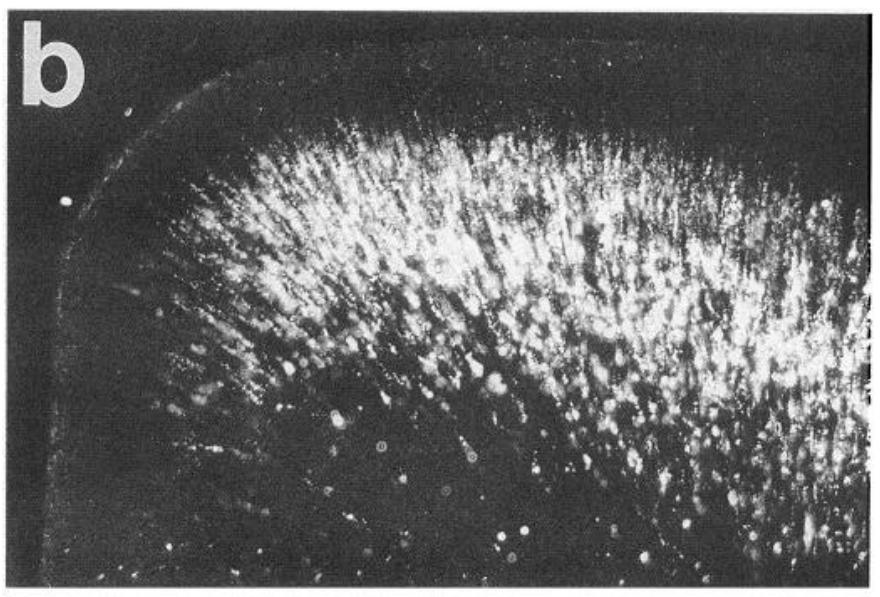

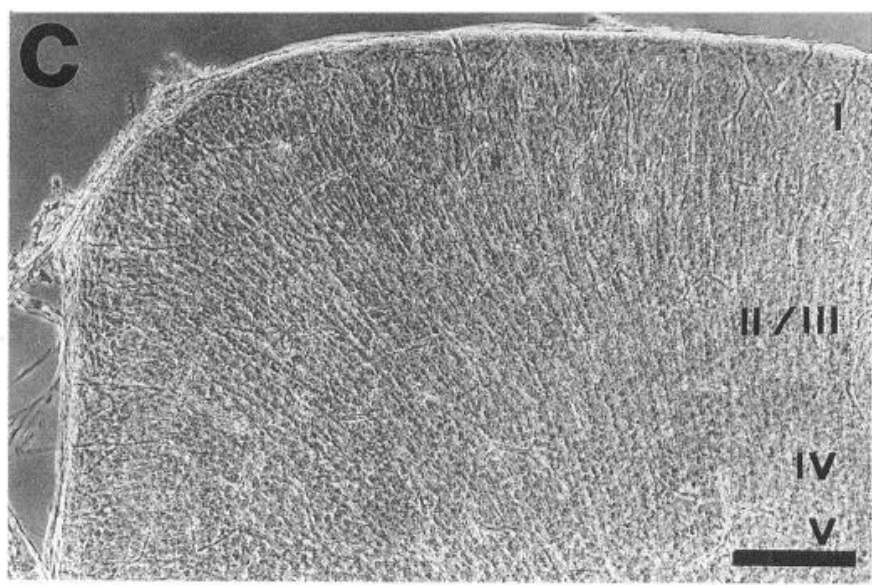

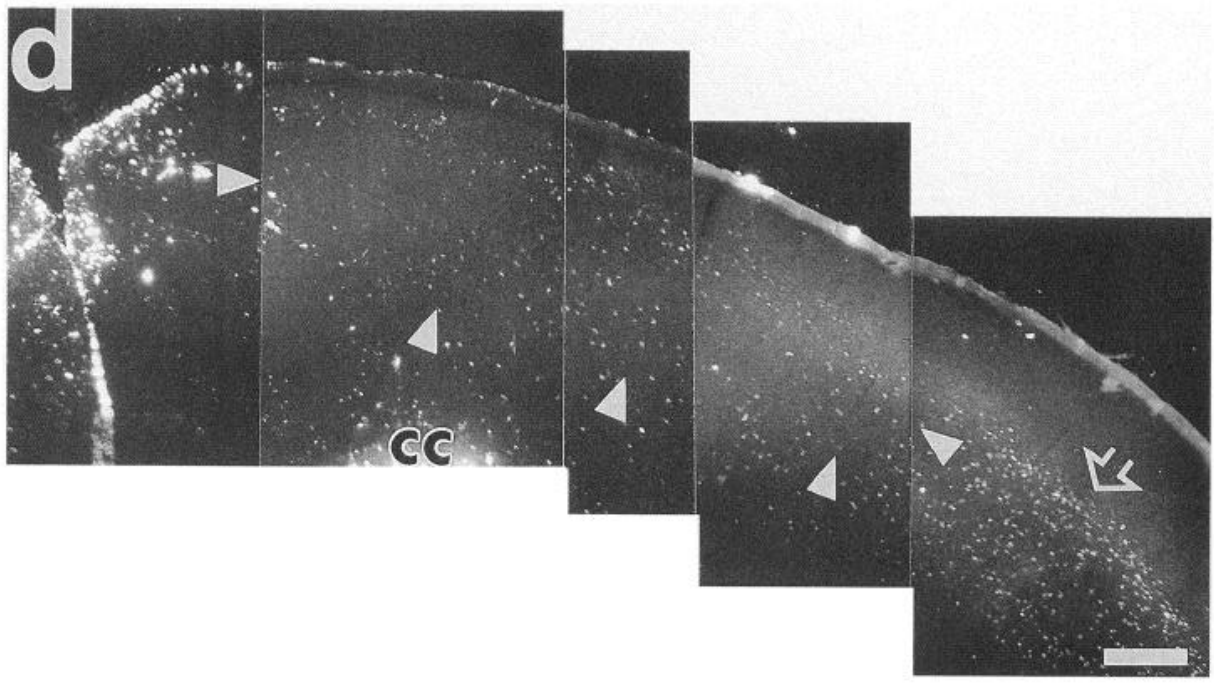
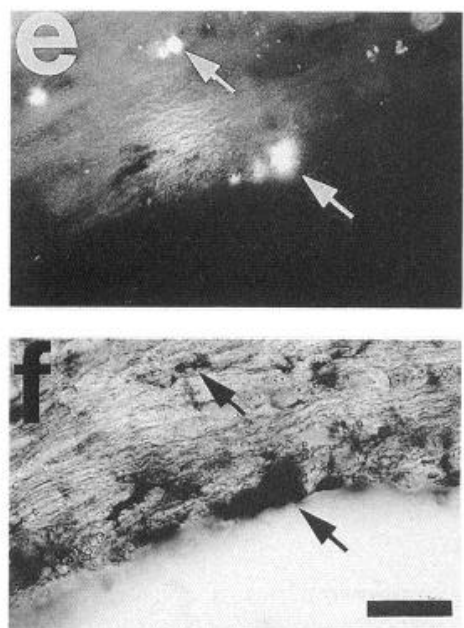

Figure 1. Experimental paradigm for transplantation of embryonic neocortical neurons into regions of targeted photolytic neuronal death in adult mice. $a$, Schematic representation of the sequential experimental steps. The photoactive chromophore chlorin $\mathrm{e}_{6}$ is injected unilaterally into motor cortex of host mice. After uptake by axonal terminals and retrograde labeling of callosally projecting pyramidal neurons (dotted pyramids), mice are transdurally exposed to near-infrared $674 \mathrm{~nm}$ laser energy via optics that delimit the geographic region of uniform exposure. Photoactivation of chlorin $\mathrm{e}_{6}$ initiates a progressive, apoptotic degeneration within labeled neurons in lamina II/III (dotted, irregular pyramids). Embryonic donor neurons (solid circles) with multiple fluorescent labels are transplanted across the thickness of neocortex. The extent of donor neuron migration and differentiation is assessed histologically and immunocytochemically from $3 \mathrm{~d}$ to 6 weeks following transplantation. $b$, Appearance under fluorescein fluorescence of retrogradely labeled pyramidal neurons in lamina II/III of motor cortex $3 \mathrm{~d}$ after injection of nanospheres carrying chlorin $\mathrm{e}_{6} . c$, Phase contrast photomicrograph of the same field, with neocortical laminae indicated. $d$, Low power fluorescence photomicrograph of neocortex 4 weeks following laser exposure reveals by the loss of neuronal fluorescence that most of the labeled neurons within regions of targeted neuronal degeneration (arrowheads) have undergone cell death and phagocytosis. Remaining fluorescence is often observed within phagocytic microglia, most frequently in the corpus callosum $(c c)$ and occasionally within the parenchyma of neocortex. Regions not exposed to light activation (open arrow) are not affected. $e$ and $f$, Higher magnification fluorescence and brightfield photomicrographs of microglia (arrows) 
Additional control transplants into host mice receiving conjugated nanosphere injections, but no laser exposure, were similarly examined 2 weeks after transplantation $(n=3)$.

Targeting of callosal projection neurons. Degeneration of neuronal subpopulations in vivo requires labeling with the photoactive chromophore chlorin $e_{6}$ that generates singlet oxygen upon noninvasive exposure to near-infrared $674 \mathrm{~mm}$ light. Retrugrade labeling of contralateral callosal projection neurons with chlorin $\mathrm{e}_{6}$ was performed with slight modifications of previously described methods (Macklis, 1993). The C57B/6J mice (PI-3 or P14-16) were deeply anesthetized through hypothermia or with Avertin, respectively. The skull was exposed by a 5$7 \mathrm{~mm}$ dorsal midline incision, and a rectangular craniotomy approximately $2 \mathrm{~mm}$ by $4 \mathrm{~mm}$ was opened to expose the dura overlying motor cortex. A series of 8-10 microinjections of fluoroscein latex nanospheres (Lumafluor) conjugated with chlorin $\mathrm{e}_{6}$ was performed unilaterally at equally spaced intervals across the length and width of motor cortex to label the callosal neurons. After all injections were performed, the overlying skin was closed with suture and the pups were returned to maternal care. Consistent with previous results (Macklis and Quattrochi, 1991; Macklis, 1993), the latex nanospheres remained localized to the injection site, thereby providing specificity of labeling, and pyramidal neurons in laminae II/III and V were labeled through retrograde transport of nanospheres conjugated with chlorin $\mathrm{e}_{6}$ (Fig. $1 b, c$ ).

Selective neuronal degeneration. After 2 weeks to allow for sufficient uptake and retrograde transport of photoactive nanospheres, host mice were deeply anesthetized with Avertin, overlying skin was incised and bilaterally reflected, and dura was exposed by craniotomy overlying the homologous region of neocortex, contralateral to the initial nanosphere injection site. Cortical illumination by a continuous wave solid state diode laser operating at $674 \mathrm{~nm}$ (Candela Laser Corp.) delivered 275$350 \mathrm{~J} / \mathrm{cm}^{2}$ of laser energy over $10-12$ minutes via a quartz optical fiber $1 \mathrm{~mm}$ in diameter with special optics (Candela Laser) to achieve crosssectional energy uniformity over a $2 \mathrm{~mm}$ diameter cortical surface. Columnation of the laser energy provided specific targeting of pyramidal neurons labeled with nanospheres only in lamina II/III and initiated a slowly progressive neuronal degeneration within this cellular subpopulation (Macklis and Madison, 1985; Madison et al., 1988; Macklis and Madison, 1991; Macklis, 1993). Regions of selective pyramidal neuron degeneration could be defined from the loss of approximately two-thirds of the pyramidal neurons containing fluoroscein flourescence 3-4 weeks following initiation of targeted neuronal death (Fig. 1d), in agreement with previous quantitative results (Macklis, 1993). Non-neuronal cellular fluorescence was also observed within these regions and in the adjacent corpus callosum, localized within microglia which were labeled by the microglia/macrophage-specific marker F4/80 (Fig. 1e,f).

In situ detection of neuronal degeneration. Neuronal degeneration following targeted cell death was assessed by both silver degeneration staining, and DNA end terminal labeling. Labeled pyramidal neurons underwent progressive cell death as early as $24 \mathrm{hr}$ following exposure to laser energy when assessed in situ for DNA fragmentation, whereas unlabeled pyramidal neurons receiving the same level of laser energy were unaffected (Fig. $2 a-e$ ). Silver degeneration staining revealed the same pattern of highly selective pyramidal neuron degeneration within lamina II/III of exposed regions, maximal at $8-10 \mathrm{~d}$ following exposure to laser energy in agreement with prior studies (Madison and Macklis, 1993).

Silver degeneration staining was performed by previously described methods (Nadler and Evenson, 1983; Madison and Macklis, 1993). Experimental mice were assessed histologically 3-14 d following exposure to incident laser energy. Mice were deeply anesthetized with Avertin, transcardially perfused with saline and heparin $(10,000 \mathrm{U} / \mathrm{liter})$ followed with $4 \%$ paraformaldehyde in $0.1 \mathrm{M}$ phosphate buffered saline $\mathrm{(pH} 7.3-$ 7.4), and postfixed for 3-8 $\mathrm{d}$ in the same fixative. The brains were blocked for coronal sectioning through regions of laser exposure, and serial sections $40-50 \mu \mathrm{m}$ thick were cut on a Vibratome (Technical Products International, Inc.). Sections were washed in water, exposed to penetrating solution (4.5\% $\mathrm{NaOH}$ and $8 \%$ ammonium nitrate), and subsequently placed in impregnating solution $(5.4 \% \mathrm{NaOH}, 6.4 \%$ ammonium nitrate, and $0.5 \%$ silver nitrate). Tissue was then rinsed in washing solution ( $30 \%$ ethanol, $0.5 \%$ sodium carbonate, and $0.1 \%$ am- monium nitrate), placed in developer $(0.05 \%$ citric acid, $0.6 \%$ formalin, and $10 \%$ ethanol), and washed in $0.5 \%$ acetic acid prior to mounting on glass slides.

End fragment labeling of DNA within degenerating neurons in situ was performed using nonisotopic DNA end-extension with digoxigeninnucleotide (Apoptag, Oncor). Experimental mice were examined $24 \mathrm{hr}$ following exposure to incident laser energy to assess the onset of neuronal degeneration. Additional control mice receiving laser energy without retrograde labeling by conjugated nanospheres were also processed to contirm prior findings that there is not nonspecific injury due to light alone (Madison and Macklis, 1993). Cryosections from fresh frozen brains were fixed with $4 \%$ paraformaldehyde $/ 0.1 \mathrm{M}$ phosphate buffered saline (PBS, pH 7.4), washed extensively in PBS, and postfixed in ethanol:acetic acid ( $/ / v 2: 1$ ). The tissue was washed in PBS and incubated with $2 \%$ hydrogen peroxide to inactivate endogenous peroxidases. Sections were then placed in equilibration buffer, reacted with the terminal deoxytransferase (TdT) enzyme, and rinsed in stop/wash buffer. After washing with PBS, cells were placed in anti-digoxigenin-peroxidase and the complex was visualized with diaminobenzidine (DAB) or DAB with cobalt and nickel chloride intensification (Pierce). Positive control samples were preincubated in DNase (1000 $\mathrm{u} / \mathrm{ml})$.

Neuronal degeneration was also seen via immunocytochemical stain ing specific for neurons. Four weeks after initiation of neuronal degeneration, staining for neuron-specific enolase (NSE) revealed that most of the remaining neurons were small, ovoid, presumptive interneurons; only rare neurons had projecting pyramidal neuron morphology. The pattern of neurofilament labeling within regions of targeted neuronal degeneration in laminae IV/III revealed a geographically defined loss of pyramidal somata and large apical dendrites, further confirming the previously reported (Macklis, 1993; Madison and Macklis, 1993) selective loss of callosally projecting neurons (Fig. $2 f$ ).

Neocortical dissection and labeling. Isolation and double fluorescent labeling of E17 neocortical neurons followed methods previously reported (Macklis, 1993). Timed E17 pregnant C57B/6J mice were cervically dislocaled, and embryos were removed and placed in calciumand magnesium-free Hanks' buffered saline solution (HBSS-CMF GIBCO), supplemented with glucose $(4500 \mathrm{mg} / \mathrm{liter})$, penicillin (24 $\mathrm{U} / \mathrm{ml}$ ), streptomycin $(24 \mathrm{mg} / \mathrm{ml})$, and Hepes butfer $(25 \mathrm{~mm})$ at $4^{\circ} \mathrm{C}$. Hemicortices were dissected, dura was removed and the cortex was minced before placing in supplemented HBSS-CMF at $4^{\circ} \mathrm{C}$. Cortical tissue was washed twice with supplemented HBSS-CMF by centrifugation at $1500 \mathrm{rpm}$ and aspiration of supernatant. Trypsin solution $(0.03 \%$ with $0.01 \%$ EDTA) was used to dissociate cells hy gentle agitation for $30 \mathrm{~min}$ at $37^{\circ} \mathrm{C}$. Cell suspensions were washed with the supplemented HBSS-CMF, and triturated in growth medium containing calcium- and magnesium-free Dulbecco's modified Eagle's medium (GIB $\mathrm{CO}$ ) with $4500 \mathrm{mg}$ glucose/liter, supplemented with penicillin (24 $\mathrm{U} / \mathrm{ml})$, streptomycin $(24 \mathrm{mg} / \mathrm{ml})$, and Hepes buffer ( $25 \mathrm{~mm})$, supplemented calf serum ( $10 \%$, Hyclone) and sodium pyruvate (1 IIIM) at $37^{\circ} \mathrm{C}$. Cells were washed again with the supplemented HBSS-CMF at room temperature, pelleted, and labeled for 30 min with supplemented HBSS-CMF solution containing nanospheres with incorporated rhodamine 6G (12.5 $\mu \mathrm{l} / \mathrm{ml}$; Madison et al., 1990; gift of Prof. C. Thies, Washington University). These nanospheres provide labeling relatively specific for neurons as identified morphologically by phase-contrast and Nomarski DIC illumination in vitro and in vivo, with neurons displaying distinct punctate granular fluorescence and glia largely unlabeled (Madison et al., 1990; Macklis, 1993). This useful specificity is not essential to interpretation of these studies, as identities of labeled neurons were confirmed morphologically and by immunocytochemical double staining. The cell suspensions were washed three times with the supplemented HBSS-CMF at $4^{\circ} \mathrm{C}$, counted during trypan blue exclusion to assure cell viability of greater than $75 \%$, and placed in a sterile vial on ice until use. To assess further the morphology and local projections of donor neurons, cells were prelabeled with the red fluorescent, lipophilic cell linker PKH26-GL (PKH26, Sigma) using recommended methods. Following transplantation, the remaining cells were plated and further monitored in vitro to assess viability and differentiation of neurons (specifically somatic morphology, neurite extension, and granular compartmentalization), thus ensuring transplantation of viable cells.

containing conjugated fluorescein nanospheres and stained for the microglial marker F4/80 within the corpus callosum. Targeted callosal pyramidal neurons have undergone apoptotic cell death and phagocytosis by microglia. Scale bars: $b-d, 200 \mu \mathrm{m} ; e$ and $f, 20 \mu \mathrm{m}$. 

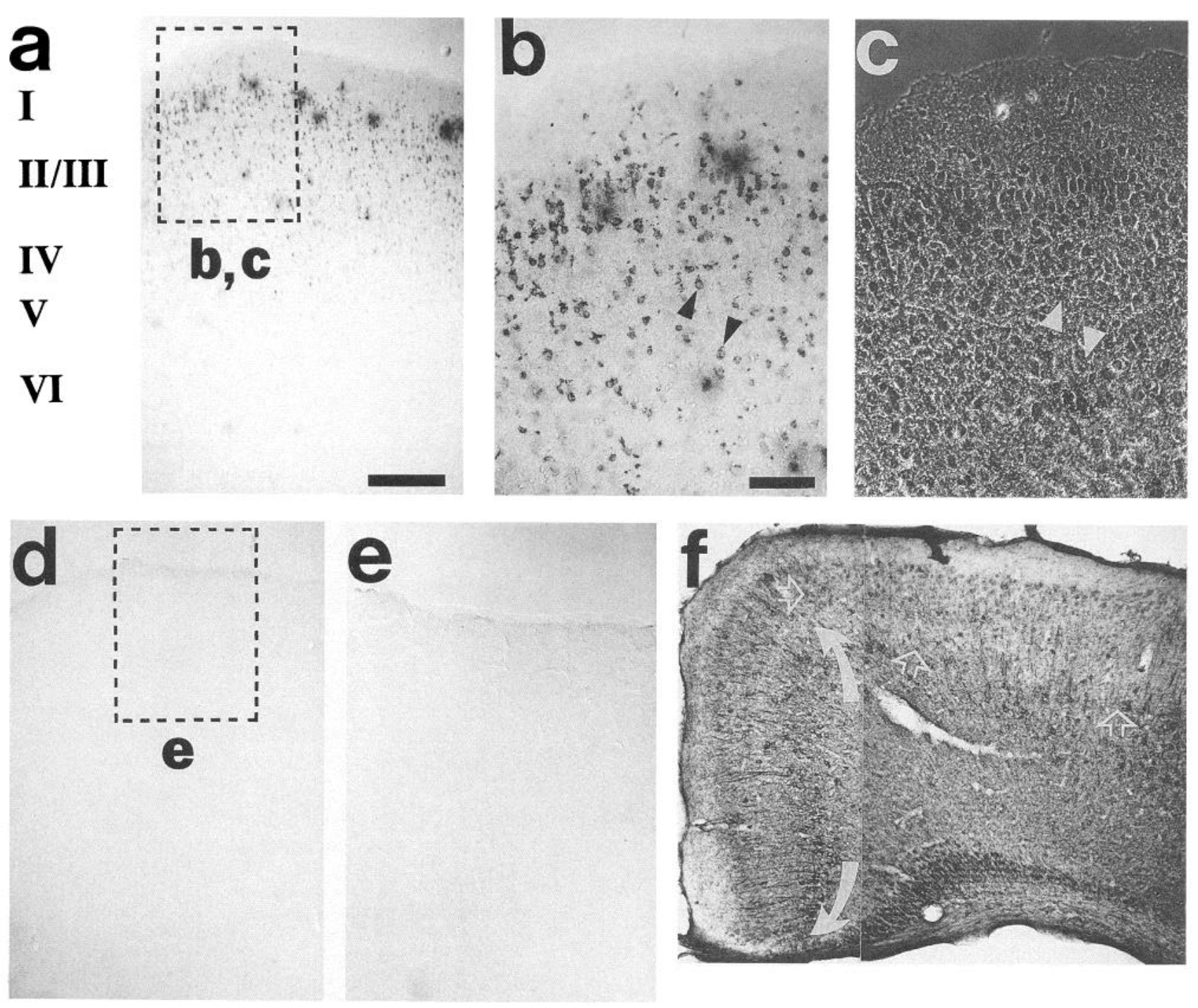

Figure 2. Pyramidal neurons in regions of targeted photolysis undergo selective, apoptotic neuronal degeneration. $a$, Degenerating neurons are stained in situ for DNA fragmentation by $3^{\prime}-\mathrm{OH}$ end terminal labeling. Apoptotic DNA fragmentation is apparent within lamina II/III 24 hr after laser exposure, and neuronal degeneration continues over 2-3 weeks, restricted to lamina II/III. The boxed region is expanded in $b$. Neocortical laminae are indicated to the left of the photomicrograph. $b$, Higher magnification photomicrograph of the boxed field in $a$, showing pyramidal neurons undergoing apoptotic degeneration (arrowheads). $c$, Phase contrast photomicrograph of the field in $b$, indicating the same degenerating pyramidal neurons (arrowheads). $d$, Photomicrograph of control neocortex $24 \mathrm{hr}$ after exposure to laser energy without targeting by chlorin $\mathrm{e}_{6}$ conjugated nanospheres. Pyramidal neurons do not undergo DNA fragmentation or degeneration, confirming that both chlorin $\mathrm{e}_{6}$ and light activation are necessary to induce cell death. The boxed region is expanded in $e$. $e$, Higher magnification photomicrograph of the boxed field in $d$, showing the absence of DNA fragmentation and degeneration of pyramidal neurons receiving light energy alone. $f$, Bright-field photomicrograph showing neurofilament staining of neocortex 4 weeks after laser exposure and initiation of targeted neuronal cell death. Loss of callosal projection neurons is further demonstrated by the reduction of neurofilament staining of large cell bodies and apical dendrites within the targeted region of neocortical lamina II/III (open arrows), compared with an immediately adjacent, nontargeted region (curved arrows). Scale bars: $a, d, f, 200 \mu m ; b, c, e, 50$ $\mu \mathrm{m}$.

Neuronal transplantation. Experimental and control mice received transplants of E17 neurons at 4 or 6 weeks of age. Cell suspensions (approximately $1 \times 10^{4} \mathrm{cells} / \mu \mathrm{l}$ ) were slowly pressure-injected into and beneath cortical regions of photolytic degeneration or intact cortex via pulled-glass micropipettes with tip diameters of approximately $100 \mu \mathrm{m}$. Micropipettes were lowered directly through the neuron deficient regions to a depth of $500 \mu \mathrm{m}$ and withdrawn over $250 \mu \mathrm{m}$ at $50 \mu \mathrm{m}$ intervals while injecting approximately $50 \mathrm{nl}$ of cell suspension at each level (total $300 \mathrm{nl}$ ) to ensure a "tubular" distribution of cells across laminae II/III to $\mathrm{V}$, thereby offering the donor neurons a laminar choice for potential migration and integration. After closing overlying skin, mice were returned to normal care until perfusion for histological analysis.

Histological analysis. We performed histological analysis from $3 \mathrm{~d}$ to 6 weeks following the transplantation of neocortical cell suspensions. Mice were deeply anesthetized with Avertin, transcardially perfused with saline and heparin (10,000 U/liter), followed with $2 \%$ paraformaldehyde in $0.1 \mathrm{M}$ phosphate-buffered saline ( $\mathrm{pH} 7.3-7.4)$, and postfixed overnight in the same fixative. The brains were blocked for coronal sectioning through regions of laser exposure and cellular transplantation, and serial sections $40-50 \mu \mathrm{m}$ thick were cut on a vibratome. Alternate sections were processed and mounted for fluorescence and cresyl violet staining to assess cellular morphology, movement from the radially oriented transplantation site, and extent of cellular integration. Fluorescence sections were air dried on gelatin-coated slides, and subsequently either dipped briefly in Histoclear (National Diagnostics) and permanently mounted in Fluoromount (Gurr), or examined directly mounted in mineral oil. Histologic examination was performed using a microscope equipped with epifluorescence and high numerical aperture optics (Zeiss).

The extent of cellular migration and differentiation was initially assessed by examination under low magnification, then in more detail 
under fluorescence, phase contrast, and Nomarski differential interference contrast (DIC) optics at high magnification to determine neuronal identity and morphology. Highly anionic nanospheres containing rhodamine $6 \mathrm{G}$ were preferentially incorporated into lysosomes of ncurons, providing a first level of neuronal identification in transplants (Madison et al., 1990). Further criteria of neuronal identification included axonal and dendritic extension, somatic morphology, and immunocytochemical analysis determined under phase contrast and Nomarski DIC optics.

Cellular locations were documented by camera lucida, and neuronal positions were digitized using a video-based image analysis system (Java, Jandel) following previously described methods (Macklis, 1993). Alternate, serial sections from experimental mice underwent quantitative analysis of the degree of migration from the transplantation site 3 days $(n=4), 1$ week $(n=2), 2$ weeks $(n=6)$, and 4 weeks $(n=2)$ after transplantation of dissociated embryonic cell suspensions $(n=$ 4069 labeled donor neurons). Of those experimental mice analyzed 2 weeks following transplantation, $n=2$ hosts were transplanted at 4 weeks of age, and $n-4$ were transplanted at 6 weeks of age. Positions of transplanted neurons within intact, control mice were digitized from serial sections 1 week ( $n=3$ mice, $n=6$ transplants), 2 weeks ( $n=$ 3 inice, $n=5$ (ransplants), and 4 weeks $(n=4)$ after transplantation to compare cellular dispersion and morphologic differentiation $(n=$ 1282 labeled donor neurons). Additional control transplants assessed positions of donor neurons within host mice receiving conjugated nanosphere injections without laser energy exposure two weeks after transplantation ( $n=3$ mice; $n=292$ labeled donor neurons). These controls evaluated whether injection of photoactive nanospheres or surgical procedures influenced the migration and differentiation of transplanted immature neurons, reproducing prior controls for these variables (Macklis, 1993).

Statistical analysis. The distributions of neuronal distance from the site of injection could be approximated by curves fit to a one-sided $\gamma$ function $\gamma(\alpha, x, n)=\left[\alpha^{n} x^{n-1} e^{-\alpha x}\right] / t(n)$ where $x$ distance from transplantation track, and $\alpha, n$ is optimized. Optima for $\alpha$ and $n$ were calculated with the Indaximum likelihood estimate $L(\alpha, n)$ for the $\gamma$ function with $L(\alpha, n)=\left[\left(\alpha^{n} x_{1}^{n-1} e^{-\alpha \times 1}\right) / t(n)\right]\left[\left(\alpha^{n} x_{2}^{n-1} e^{-\alpha \times 2}\right) / t(n)\right] \ldots$ Maxima were obtained by the differentiation of $L(\alpha, n)$ with respect to $\alpha$ and $n$ and determining $\alpha$ and $n$ for $\delta L / \delta \alpha=0$ and $\delta L / \delta n=0$ for the respective distributions (B. Nalebuff, personal communication).

Immunocytochemistry. Immunocytochemical staining for neuron specific enolase (NSE; Zymed), neurofilament (NF, pan-neuronal nonphosphoneurofilament-specific, Sternberger; and NF, pan-neuronal, Zymed), or the macrophage specific marker F4/80 (gift of Dr. A. Fzekowitz) was performed on cryosections of brains fixed in $4 \%$ paraformaldehyde and cryopreserved with sucrose, or Vibratome sections of brains fixed with $2-1 \%$ paraformaldehyde. Sections were rinsed in PBS containing $0.25 \%$ Triton X-100 and $1 \%$ goat serum, incubated in block solution (10\% goat serum in PBS), and placed into the primary antibodies (stock NSE; $1: 200$ $\mathrm{NF} ; 1: 20 \mathrm{~F} 4 / 80$ ) for $2-3 \mathrm{~d}$ at $4^{\circ} \mathrm{C}$. The tissue was then washed in blocking solution, and processed according to the peroxidase $\mathrm{ABC}$ kit (Vectastain). Neurofilament, NSE, and F4/80 staining were visualized with a DAB substrate alone or a DAB substrate enhanced by nickel and cobalt chloride (Pierce). Donor neurons were identified by rhodamine fluorescent nanosphere labeling within antibody stained tissue sections.

\section{Results}

Transplantation of E17 neocortical neurons into intact adult cortex

Donor E17 neurons in intact regions of adult mouse neocortex showed an extremely limited extent of migration and integration 1-4 weeks following transplantation. Donor neurons spanning laminae II/III to $\mathrm{V}$ remained localized to the site of injection (Fig. $3 a-d, f$ ). Donor neurons were located at an average distance of $23 \pm 18 \mu \mathrm{m}$ from the transplantation track with a maximal spread of $140 \mu \mathrm{m}$. There was no significant change in distribution of donor neurons over time. The distribution of neuronal positions was similar but slightly more restricted than in the previously reported control transplants into juvenile hosts (Macklis, 1993). This minor difference may be explained by ongoing growth of the brain in juvenile hosts. The positions of E17 neurons transplanted into neocortex of mice following injections of photoactive nanospheres without light exposure did not differ significantly from transplants into intact mice (Fig. $3 e$ ).

Morphologically, donor neurons in all controls remained small and ovoid with only localized process extension, resembling endogenous interneurons in size and morphology (Fig. 4). Donor neurons could be identified by combined immunocytochemical staining for NSE and labeling with rhodamine fluorescent nanuspheres, demonstrating the diminished size and interneuron morphology of transplanted neurons compared with host pyramidal neurons (Fig. 4d,e). Niss1 staining further demonstrated the nonpyramidal morphology of donor neurons near the sites of transplantation, compared with host pyramidal neurons further from the injection track (Fig. $4 f$ ).

\section{Transplantation of E17 neocortical neurons into regions of adult cortex undergoing targeted neuronal degeneration}

Embryonic (E17) donor neurons within the regions of targeted neuronal death in adult mice displayed strikingly different behavior by undergoing directed migration and differentiation $3 \mathrm{~d}$ to 2 weeks after transplantation, without further migration observed 4 and 6 weeks after transplantation. Three days to 1 week after transplantation into experimental host mice, clusters of donor embryonic neurons could be observed with elongated morphologies within regions of targeted cell death and in locations midway between the transplantation track and the photolytically targeted regions, suggesting that these neurons were still undergoing an active process of migration at these times (Fig. $5 a, b$ ). These included clusters oriented obliquely in deeper laminae IV and V, migrating across these layers to their final locations. One to 2 weeks following transplantation, neurons resided in lamina II/III (Fig. 5c,d). Donor neurons within regions of photolytic degeneration displayed a directed and specific migration into neocortex undergoing targeted cell death over the first 2 weeks (Fig. 6a,b). Donor neurons $3 \mathrm{~d}$ after transplantation had a mean distribution of $39 \pm 31 \mu \mathrm{m}$ from the transplantation track. The mean distribution of donor neurons increased to $96 \pm 94 \mu \mathrm{m}$ from the transplantation track one week following transplantation, with $42 \%$ of the cells lying beyond $3 \mathrm{SDs}$ of the mean from the control cases (Fig. 6d). After 2 weeks, quantitative analysis of neuronal distance from the transplantation track of experimental mice indicated an average neuronal dispersion of $86 \pm 74 \mu \mathrm{m}$ (Fig. $6 e$ ). Neuronal positions 2 weeks after transplantation into 4 week old or 6 week old hosts did not differ significantly by 2 weeks (Fig. 6e). Four weeks after transplantation, donor neurons were positioned $102 \pm 93 \mu \mathrm{m}$ from the transplantation track with a maximal migration of $430 \mu \mathrm{m}$ perpendicular to the track (Fig. $6 f$ ). In comparison with control populations, $45 \%$ and $48 \%$ of neurons in experimental mice 2 and 4 weeks after transplantation were distributed more than 3 SDs beyond the mean for control distributions. Donor neurons 6 weeks following transplantation displayed a qualitatively similar distribution and reintegration into neuron-deficient regions in lamina II/III.

The experimental distributions obtained for neuronal distance from the site of injection could be approximated by curves fit to a one-sided gamma function $\gamma(\alpha, x, n)$ where $x$ is distance, $\alpha, n$ is optimized (B. Nalebuff, personal communication). Both control and experimental cases were best fit to the gamma function $\gamma(n=1)$, which approximates an exponential decay. Control cases, 4 weeks following transplantation, exhibited a modified exponential density with mean of $20 \mu \mathrm{m}$ from the transplantation site ( $\alpha=0.05$ ), differing significantly from the experimental 

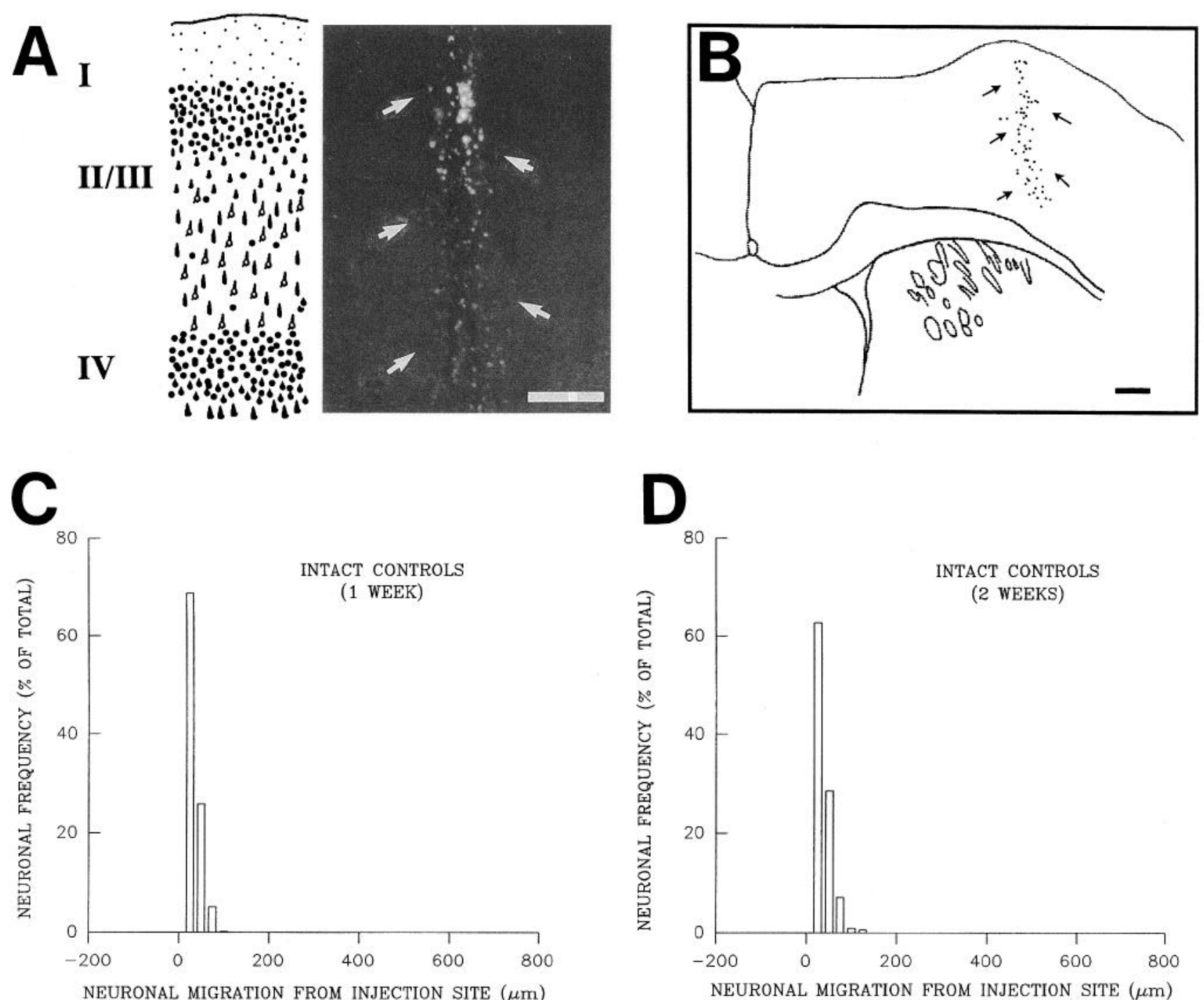

NEURONAL MIGRATION FROM INJECTION SITE $(\mu \mathrm{m})$

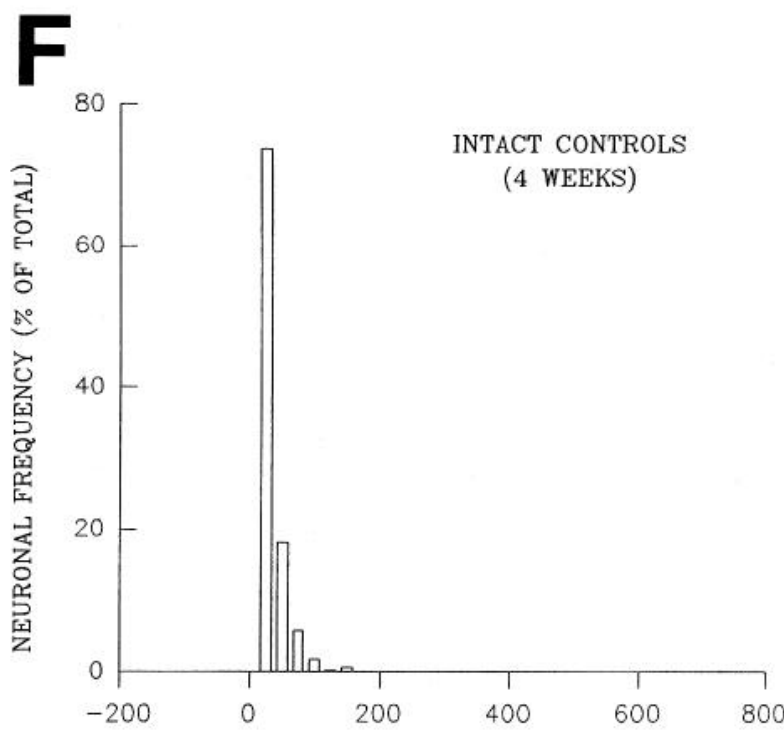

NEURONAL MIGRATION FROM INJECTION SITE $(\mu \mathrm{m})$

NEURONAL MIGRATION FROM INJECTION SITE $(\mu \mathrm{m})$

Figure 3. Quantitative analysis of donor neuron positions following transplantation into control cortex of adult mice. $a$, Fluorescence appearance of transplanted neurons within an intact control mouse 2 weeks following transplantation. Donor neurons remain highly confined to the transplantation site (arrows). Corrresponding neocortical laminae are indicated to the left. $b$, Representative camera lucida drawing demonstrates the positions 

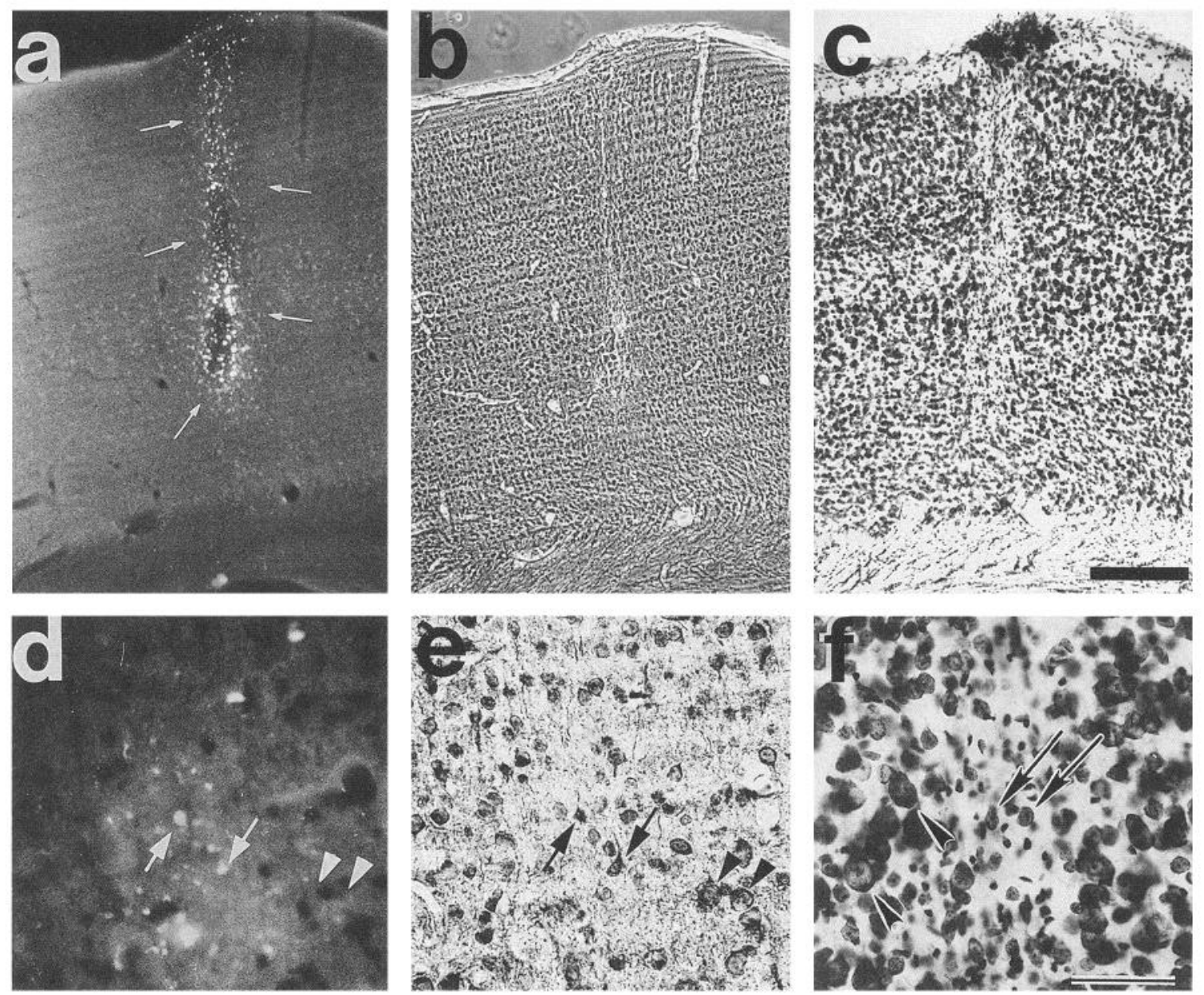

Figure 4. Nonpyramidal morphology of transplanted neurons within control intact neocortex of adult mouse. $a$ and $b$, Fluorescence and phase contrast photomicrographs of embryonic day 17 (E17) neocortical neurons 2 weeks following transplantation into intact cortex. Neurons are small in size and show extremely limited dispersion from the transplantation track (arrows). $c$, Nissl stain of an adjacent section similarly demonstrates small, ovoid donor neurons, spanning laminae II/III to $\mathrm{V}$ and remaining highly localized to the site of transplantation. $d$ and $e$, Higher magnification fluorescence and brightfield photomicrographs of donor neurons stained for neuron-specific enolase. Morphologically, donor neurons (arrows) appear small and ovoid with only localized process extension, resembling endogenous interneurons in size and morphology, compared with much larger, characteristic pyramidal neurons of the host (arrowheads). $f$, Higher magnification photomicrograph of the Nissl stained section in $c$ shows that the donor neurons (arrows) remain small and ovoid, unlike the endogenous pyramidal neurons of the host (arrowheads). Scale bars: $a-c, 200 \mu \mathrm{m} ; d-$ $f, 50 \mu \mathrm{m}$.

cases, examined 2 or 4 weeks after transplantation, which follow a modified exponential with mean of $100 \mu \mathrm{m}$ from the transplantation site $(\alpha=0.01)$. The mean distance migrated by donor neurons following transplantation into regions of targeted cell death was therefore greater than and differed significantly from the mean dispersion for donor neurons transplanted into intact cortex.

\section{Morphology and local projections of transplanted neurons in regions of targeted photolytic neuronal death}

Repopulation of the neocortex was limited to regions of photolytic degeneration within lamina II/III, with many transplanted neurons displaying extension of axons and dendrites, and integration into host neocortex (Fig. 7). Local projections of donor neurons labeled with the lipophilic dye PKH26 within regions of targeted cell death were often appropriately oriented, with apical dendrites and axons. Transplanted neurons displayed characteristic pyramidal neuron morphology under fluorescence and Nomarski DIC, with large cell somas, large nuclei, and prominent nucleoli. Dendritic branching often extended toward the pial surface, while axons could be seen to project for several hundred micrometers toward the corpus callosum. Donor neurons were distinctly identified by granular, rhodamine fluorescence, and they assumed a large, pyramidal phenotype similar

$\leftarrow$

of neurons from another control mouse 2 weeks after transplantation into intact neocortex. Neurons exhibit extremely limited dispersion from the site of injection (arrows). $c, d, f$, Neurons transplanted into intact neocortex remain highly localized to the transplantation site $1-4$ weeks following transplantation. Neuronal positions were digitized from camera lucida drawings, measured perpendicularly from the injection track. Donor neurons are located an average of $23 \mu \mathrm{m}$ from the transplantation track with a maximal spread of $140 \mu \mathrm{m}$. $e$, The positions of donor neurons transplanted into neocortex of control mice following injections of photoactive nanospheres without light exposure did not differ significantly from transplants into intact mice. Scale bars: $a, 150 \mu \mathrm{m} ; b, 250 \mu \mathrm{m}$. 

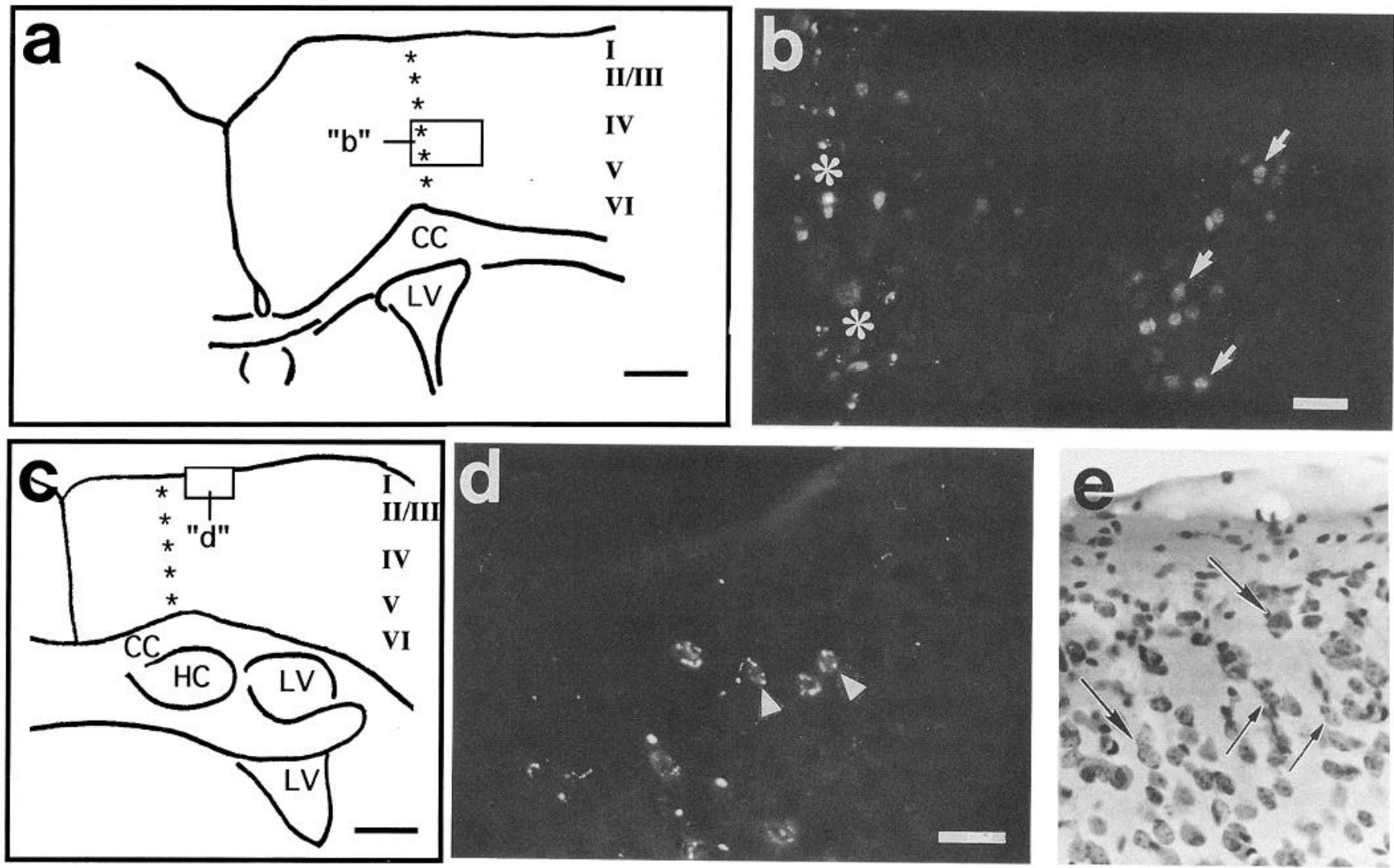

Figure 5. Progressive migration of transplanted embryonic neurons into regions of targeted neuronal degeneration in neocortex of adult mice. $a$, Camera lucida drawing for orientation, including the transplantation site (asterisks) within a region of targeted cell death, 1 week following transplantation. The boxed field is shown at higher magnification in the adjacent fluorescence photomicrograph $b$. $C C$, Corpus callosum; $L V$, lateral ventricle; neocortical laminae are indicated. $b$, Higher magnification fluorescence photomicrograph of the boxed field in $a$. In mice with targeted neuronal degeneration in lamina II/III, 1 week following transplantation, clusters of immature neurons are seen migrating from the injection track (asterisks). These include clusters oriented obliquely in layer IV (arrows), migrating across this layer to their final locations in lamina II/III. c, Camera lucida drawing for orientation, including the transplantation site within a region of targeted cell death, 2 weeks following transplantation. The boxed field is shown at higher magnification in the adjacent fluorescence photomicrograph $d$. $C C$, corpus callosum; $L V$, lateral ventricle; $H C$, hippocampus; neocortical laminae are indicated). $d$, Higher magnification fluorescence photomicrograph of the boxed field in $c$. Two weeks after transplantation, donor neurons assume positions within neuron-deficient regions in lamina II/III and differentiate into pyramidal neurons. $e$, Nissl stain of the same field in an adjacent section demonstrates donor neurons within superficial lamina II/III with large pyramidal morphology (large arrows), laterally dispersed from the injection track. Donor neurons with pyramidal neuron morphology are interspersed with endogenous host interneurons (small arrows). Scale bars: $a$ and $c, 500 \mu \mathrm{m} ; b, 50 \mu \mathrm{m} ; d$ and $e, 40 \mu \mathrm{m}$.

to remaining, endogenous pyramidal neurons when examined under Nomarski DIC optics. Large cell diameters ranging from $12-25 \mu \mathrm{m}$, and fluorescent labeling at the periphery of the cell soma and into the proximal processes, indicated neuronal identity. In contrast, neurons remaining at the site of transplantation, or transplants into intact neocortex, typically remained small and ovoid with presumptive interneuron morphology. The frequent observations of donor neurons in experimental mice with typical pyramidal neuron morphology and appropriate local projections support a directed reintegration and repopulation of neuron deficient regions.

\section{Expression of neuron-specific markers by donor neurons within regions of targeted cell death}

The integration and differentiation of donor neurons were further confirmed by antibody labeling with the neuron-specific markers

Figure 6. Quantitative analysis of donor neuron positions following transplantation into experimental adult mice undergoing targeted neuronal degeneration. $a$, Fluorescence appearance of transplanted neurons within regions of neuronal degeneration two weeks following transplantation. Donor neurons (arrows) selectively repopulate these neuron-deficient regions in lamina II/III. $b$, Representative camera lucida drawing of neuronal positions from another experimental mouse 2 weeks following transplantation. Repopulation by transplanted neurons is limited to the region of targeted neuron death in lamina II/III (arrows). $c$, Three days after transplantation into and beneath regions of targeted degeneration, donor neurons begin migration beyond the distribution of neurons in controls. $d$, One week following transplantation into regions undergoing degeneration, donor neurons are distributed widely from the transplantation site. Approximately $45 \%$ of the neurons are positioned beyond 3 SDs of the mean for controls, migrating throughout regions of neuronal degeneration. $e$ and $f$, Donor neurons 2 and 4 weeks following transplantation into regions of targeted degeneration migrate slightly further, and fewer donor neurons remained within $50 \mu \mathrm{m}$ of the transplantation site, suggesting ongoing migration between $3 \mathrm{~d}$ and 2 weeks after transplantation. Transplants into 4 and 6 week old mice show no significant difference in neuronal migration from the injection site at two weeks after transplantation. Scale bars: $a, 150 \mu \mathrm{m} ; b, 250 \mu \mathrm{m}$. 

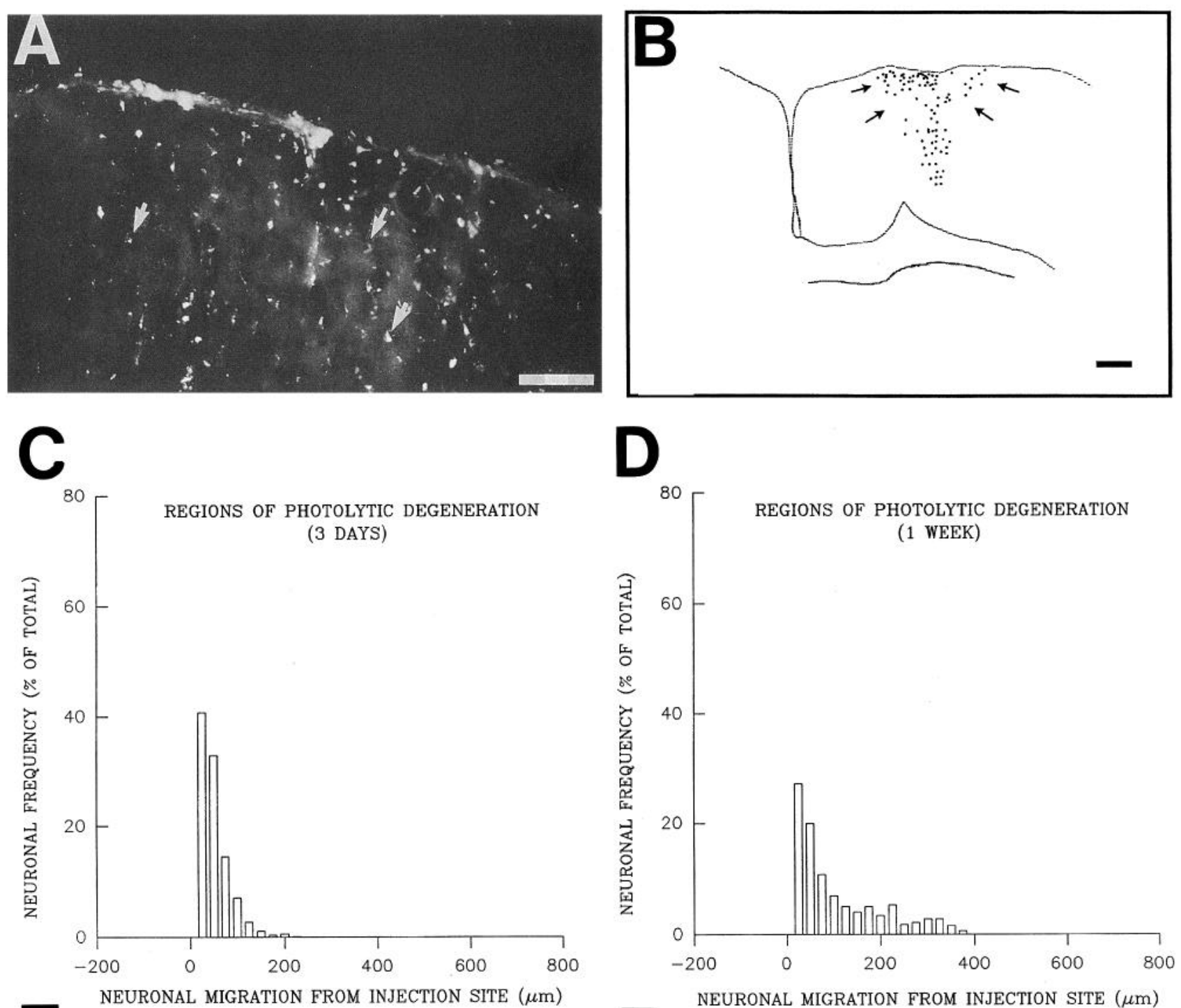
NEURONAL MIGRATION FROM INJECTION SITE $(\mu \mathrm{m})$

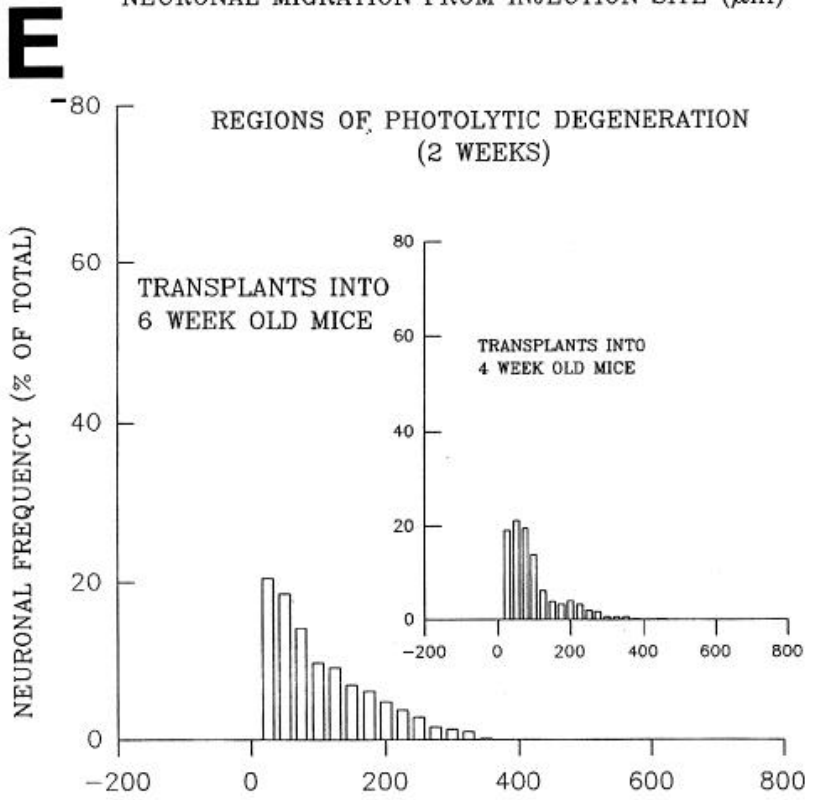

NEURONAL MIGRATION FROM INJECTION SITE $(\mu \mathrm{m})$

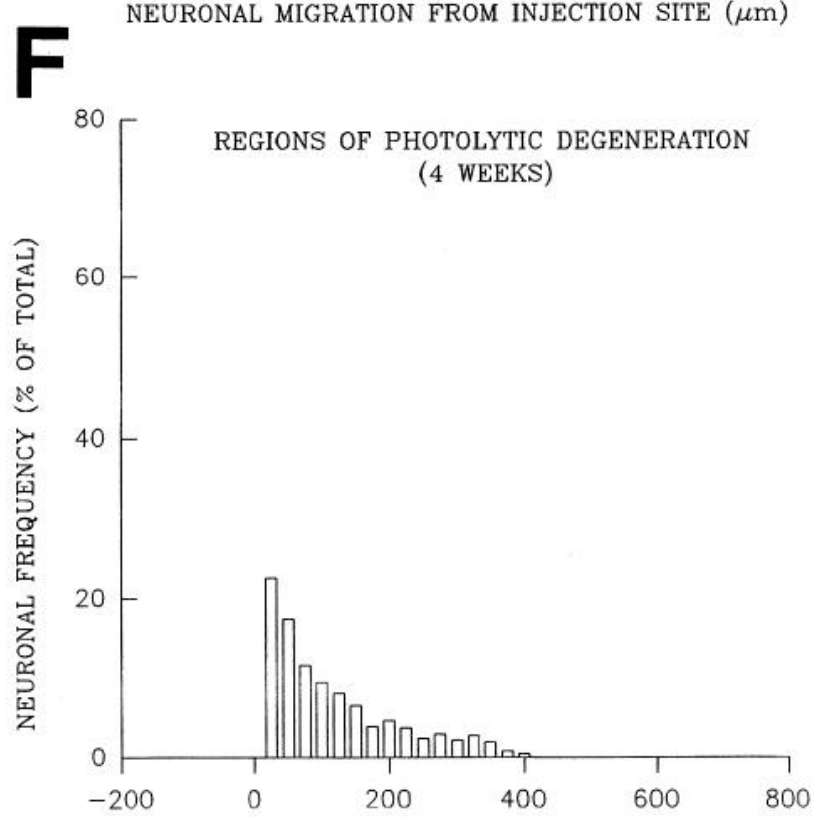

NEURONAL MIGRATION FROM INJECTION SITE $(\mu \mathrm{m})$ 
Figure 7. Pyramidal morphology and local projections of donor neurons within regions of targeted photolytic neuronal cell death. $a$ and $b$, Fluorescence photomicrographs of transplanted neurons, labeled with the lipophilic dye $\mathrm{PKH} 26$, within the neuron-deficient regions. The neurons (open arrows) display characteristic pyramidal neuron morphology including axons (large arrows) extending ventrally to the corpus callosum, and apical dendrites (small arrows) oriented dorsally toward the pial surface. $c$, Fluorescence image of a donor neuron (large arrow) labeled with PKH26, revealing the apical dendrite (small arrows). $d$, Appearance of the same donor neuron (large arrow) under Nomarski DIC optics reveals a large soma, large nucleus, and prominent nucleoli (arrowhead). The base of a large apical dendrite is outlined (small arrows). $e$ and $f$, Fluorescence appearance of a transplanted neuron (open arrow) in two focal planes, illustrating the ventral extension of the axon (large arrows) toward the corpus callosum and dorsal extension of the dendrite (small arrows) toward the pial surface. Scale bars: $a$ and $b, 25 \mu \mathrm{m} ; c$ and $d, 15 \mu \mathrm{m} ; e$ and $f, 25$ $\mu \mathrm{m}$.
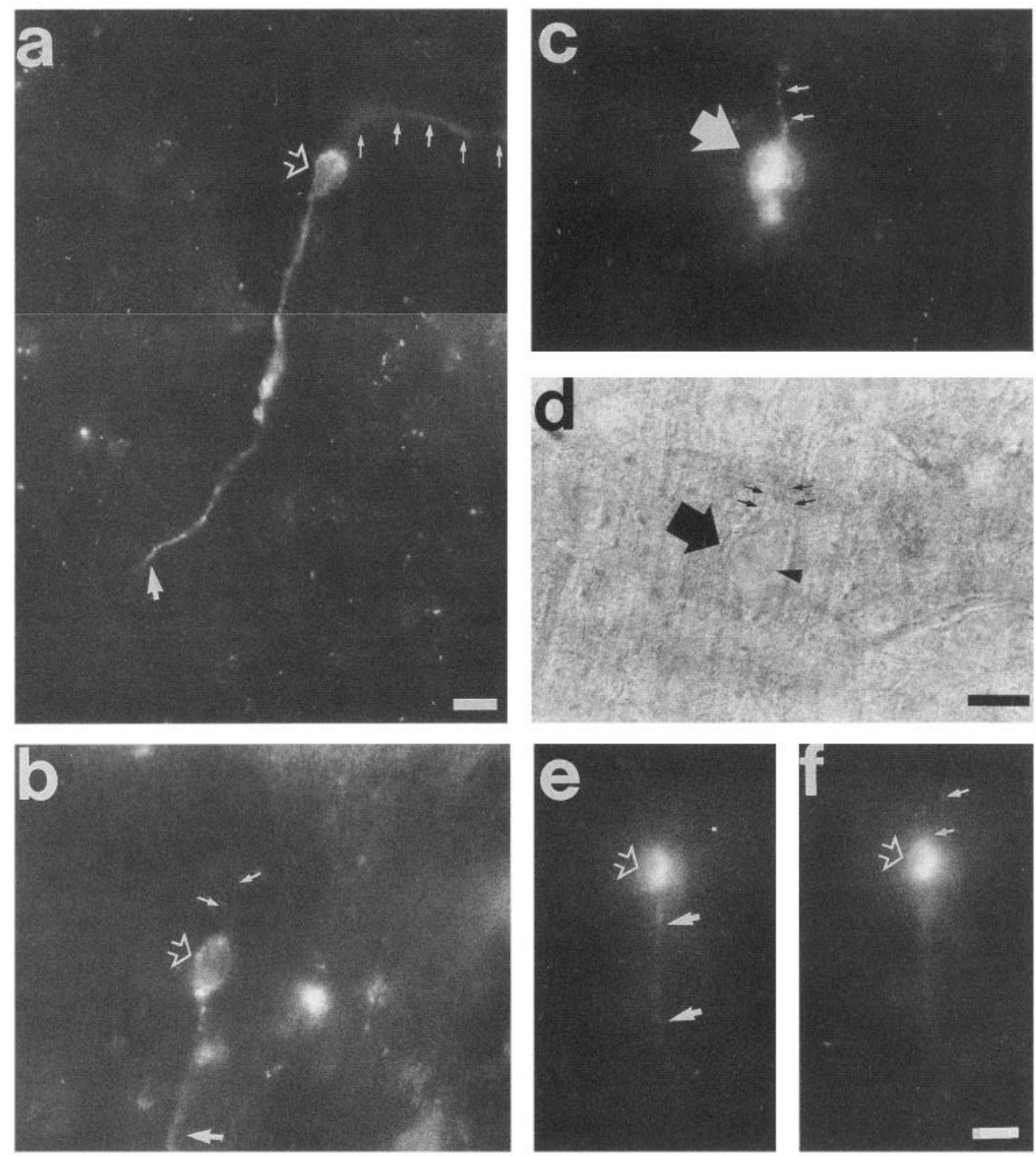

NSE and NF. Donor neurons had cell body diameters characteristic of differentiated pyramidal meurons, displayed prominent axons and dendrites, and were widely dispersed within regions of targeted neuronal degeneration (Fig. 8). Neuron-specific enolase displayed most intense staining within the neuronal cytoplasm, leaving the nucleus and processes largely unlabeled. Staining by NSE within cells containing granular nanosphere fluorescence supported the morphologic criteria used to identify transplanted neurons, determined by large cell somas, nuclei and prominent nucleoli (Fig. $8 c, d$ ). Neurofilament staining exhibited a characteristic fibrillar pattern in neuronal processes with intense staining in the soma. Neurons of donor origin showed both fluorescent nanosphere labeling and NF staining in processes which were often oriented radially toward the pial surface and corpus callosum (Fig. 8e,f). The pattern of neuronal immunocytochemical labeling within donor neurons was indistinguishable from endogenous pyramidal neurons, further indicating appropriate integration and directed differentiation into pyramidal neuron phenotype within regions of targeted neuronal cell death.

\section{Discussion}

Our results that targeted photolytic neuronal death in adult mice produces directed migration and differentiation of transplanted embryonic neurons provide evidence for selectively altered expression of molecular signals that are usually developmentally regulated. The transplanted embryonic neurons in areas undergoing targeted apoptosis underwent a sequence of migratory, differentiation, and integration events appropriate to the initial development of the superficial lamina II/III. These events did not occur in control mice. Clusters of embryonic neurons began migrating away from the transplantation track within $3 \mathrm{~d}$ after transplantation, and migration up to $430 \mu \mathrm{m}$ was largely complete by 2 weeks. The subpopulation of neurons repopulating the regions of photolytic degeneration underwent directed differentiation into pyramidal neurons when compared to neurons remaining at the transplantation site or in control mice, which resembled endogenous interneurons. The finding of extremely limited migration by donor neurons in intact adult mice is consistent with previous studies in which embryonic neurons transplanted into intact juvenile mice were maximally dispersed and morphologically differentiated by 2-3 weeks following transplantation (Macklis, 1993), and with results from the extensive literature involving grafts into the parenchyma of neocortex in postmigrational and adult hosts. Together, these findings suggest that alterations in the host microenvironment, possibly due to loss of cell-cell and/or cell-matrix interactions, can be elicited 

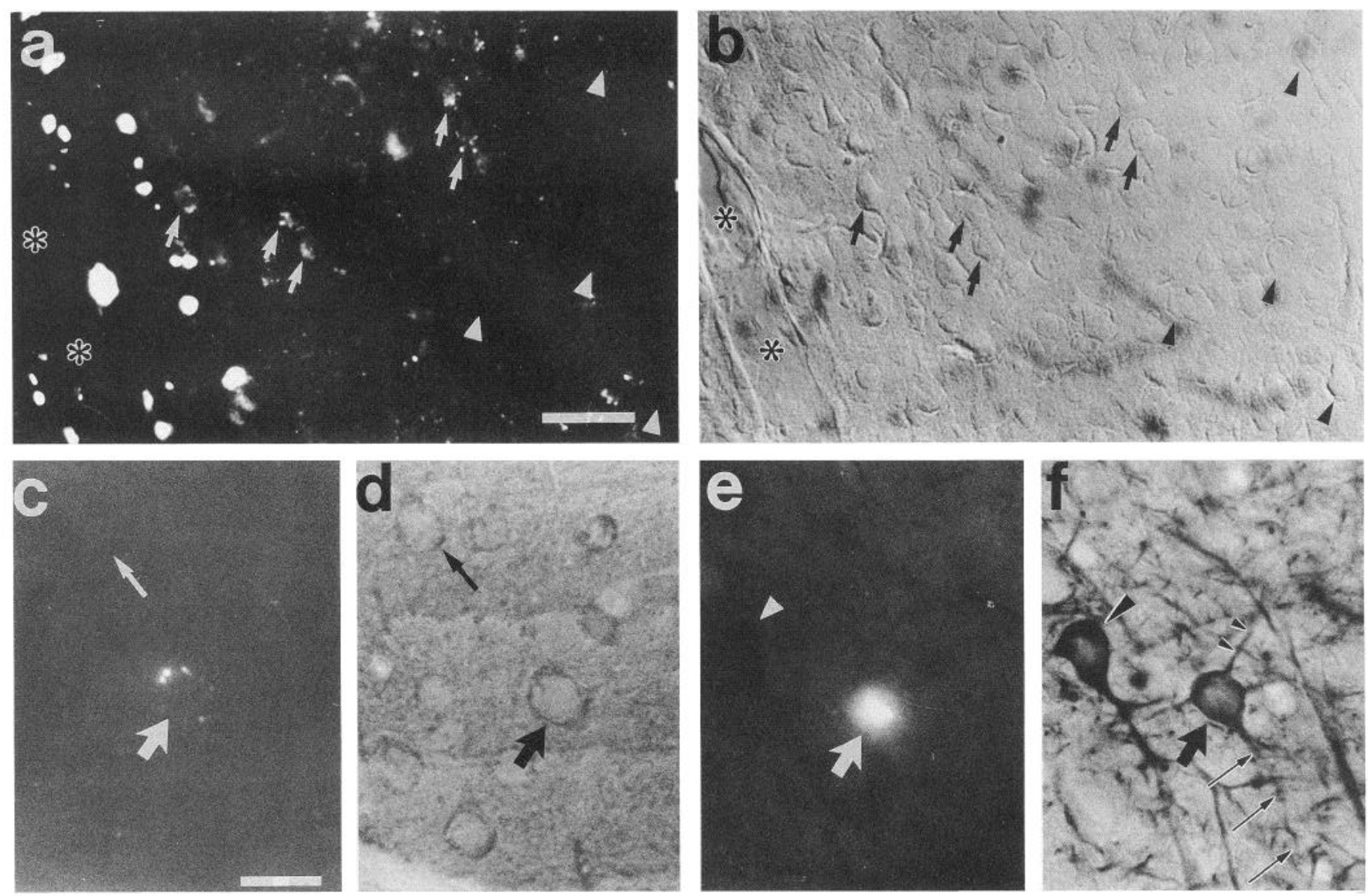

Figure 8. Expression of neuron-specific antigens by donor neurons within regions of targeted neuronal degeneration. Fluorescence photomicrograph demonstrates donor neurons labeled with rhodamine fluorescent nanospheres (arrows), laterally dispersed from the transplantation site (asterisks) 2 weeks after transplantation. Unlabeled, remaining endogenous neurons are indicated (arrowheads). $b$, The same donor neurons (arrows) assume a large pyramidal morphology indistinguishable from remaining, endogenous pyramidal neurons (arrowheads) when examined under Nomarski DIC optics. $c$ and $d$, A transplanted neuron (large arrow), identified by intracellular fluorescence in $c$, is double stained for neuron-specific enolase (NSE) in $d$. Neuron-specific enolase displays most intense staining within the cytoplasm, leaving the nucleus and processes largely unlabeled. The pattern of NSE staining observed in donor neurons within regions of neuronal degeneration is identical to that of the remaining endogenous pyramidal neurons (small arrow). $e$ and $f$, Fluorescence and bright field images of a transplanted neuron (large arrow) immunocytochemically stained for neurofilament. Neurofilament staining is localized within the periphery of the soma and within axons (arrows) and dendrites (small arrowheads), properly oriented toward the corpus callosum and pial surface, respectively. Donor neurons resemble endogenous, host neurons (large arrowhead), assuming large pyramidal morphology within regions of targeted neuronal degeneration. Scale bars: $a$ and $b, 50 \mu \mathrm{m} ; d-f, 20 \mu \mathrm{m}$.

in neocortex of fully adult mice and in turn, influence the migration, differentiation, and integration of transplanted immature neurons.

The extent of migration and differentiation by donor neurons within regions of targeted photolytic neuronal death in adult hosts was similar to that seen in juvenile mice (Macklis, 1993). This supports the hypothesis that the specific loss of neurons by photolytically induced apoptosis can activate intercellular signal changes leading to plasticity independent of host age. Both studies demonstrate a preferential migration and assumption of pyramidal neuron morphology, limited to the region undergoing targeted photolytic neuronal degeneration in lamina II/III. Donor neurons partially restored normal cortical architecture by repopulating neuron-deficient regions. Neurons placed adjacent to regions of photolytic degeneration in juvenile mice migrated up to $780 \mu \mathrm{m}$ perpendicularly from the transplantation track. Neurons centrally located in regions of photolytic degeneration in adult mice migrated up to $430 \mu \mathrm{m}$ perpendicularly from the transplantation track. These perpendicular measurements may be underestimates of the true migration distances; neurons with oblique trajectories would be expected to migrate over consideraly longer distances (approximately 600-700 $\mu \mathrm{m}$ ). The difference observed between adolescent and adult hosts may also simply be due to the change in experimental paradigm, since cell suspensions in the present experiments were transplanted through the center of the regions of neuronal degeneration rather than adjacent to these zones. The modification effectively halves the lateral dimension of regions of degeneration into which neurons may migrate, while increasing the probability of successful engraftment into a region of targeted cell death. The results of these experiments in adult mice provides an opportunity to isolate the molecular alterations in adults with less potential confusion by unrelated late elements of the normal developmental timetable that could be present in younger mice.

Several observations demonstrate that the labeled neurons are indeed the donor neurons. Evidence from the current experiments argues in three ways for specific identification of neurons of donor origin and against nonspecific labeling of host neurons by accumulation of free label following transplantation or from release of label by dying or lysed donor cells. (1) Neurons la- 
beled with the neuron-selective, rhodamine fluorescent nanospheres or the lipophilic dye PKH26 are located distant from the transplantation site selectively within regions of targeted cell death in superficial lamina II/III while labeled neurons in deeper cortical layers remain extremely close to the site of injection. Nonspecific uptake of either label by host neurons would not show laminar preference. (2) The intensity of labeling following direct application of fluorescent nanospheres or $\mathrm{PKH} 26$ in vitro leads to distinct and more pronounced labeling of donor neurons than is observed following nonspecific uptake and labeling of host neurons at a nanosphere injection site in vivo. (3) Neurons transplanted into regions of targeted cell death morphologically assume a pyramidal phenotype. Nonspecific uptake of the fluorescent labels would be expected to occur in both interneurons and pyramidal neurons far from the transplantation site. Further evidence derives from prior control studies of labeled, hypoosmotically lysed neocortical neurons and neuroblastoma cells, viable neocortical neurons, and viable cerebellar neurons transplanted into intact cortex (Macklis, 1993); these experiments did not exhibit lamina-specific migration and differentiation of donor neurons. Similarly, labeled neocortical neurons transplanted into kainic acid lesioned hosts did not display directed migration or differentiation by donor neurons. When lysed neurons did release their contents within the host brain, non-neuronal phagocytes engulfed and cleared the debris, as observed by fluorescence and electron microscopy. Taken together, such findings argue strongly against the possibility of widespread, nonspecific uptake of fluorescent nanospheres or PKH26 by host neurons.

Our results add additional support to the concept of microenvironmental regulation of neuronal migration and differentiation. The directed behavior of donor neurons is sharply limited to the regions of targeted degeneration, their development is not autonomous, and local alterations can support their migration and differentiation even in adult mice. Our results are consistent with results seen using other systems of neuronal injury within the central nervous system. Embryonic cerebellar Purkinje cells, transplanted into cerebellum of adult Purkinje cell degeneration (PCD) mutant mice, display elements of appropriate positional and temporal specificity in repopulating neuronally depleted regions (Sotelo and Alvarado-Mallart, 1986, 1987, 1988; Gardette et al., 1988; Sotelo et al., 1994). Many anatomic lesioning experiments reveal similar but more limited elements of plasticity within the host environment when appropriate embryonic neurons are transplanted into the affected sites (Itakura et al., 1990; Stromberg et al., 1992; Takeuchi et al., 1992; Cenci et al., 1993; Groves et al., 1993). Directed differentiation is observed in the goldfish retina system (Braisted and Raymond, 1992, 1993), where laser ablation of retinal cone photoreceptors leads to specific regeneration of cone photoreceptors and repopulation of the lesioned area (Braisted et al., 1993).

Microenvironmental control over neural cell fate has become increasingly supported by experimental evidence from recent transplantation studies of both primary neurons and genetically modified precursor cell lines. Primary cerebellar precursor cells can shift fate by differentiating into neurons with hippocampal phenotype upon transplantation into neonalal dentate gyrus (Vicario et al., 1993), while striatal precursors transplanted into the embryonic cortical ventricular zone generate neurons with cortical phenotypes (Fishell, 1993). Similarly, immortalized multipotent precursor cells undergo differentiation appropriate for the site of implantation within the neonatal hippocampus, neonatal cerebellum, and adult striatum (Renfranz et al., 1991; Snyder et al., 1992; Sheen et al., 1993, and unpublished observations). Studies of the immortalized C17-2 precursors (Snyder et al., 1992) derived from neonatal cerebellum implanted into intact neocortex, and along the neuraxis, of mice at various times during development and postnatal life indicate that differentiation into neuronal phenotype is limited to the period of neurogenesis within a particular CNS region (Snyder et al., 1993 and unpublished observations). Transplants of C17-2 cells into adult intact and kainic acid lesioned neocortex did not receive the necessary local cues to initiate any neuronal differentiation, but they underwent directed differentiation into both neurons and glia following transplantation into regions of targeted photolytic neuronal death (Macklis et al., 1994; E. Y. Snyder, C. H. Yoon, J. D. Flax, and J. D. Macklis, unpublished observations). The plasticity observed following targeted photolytic neuronal death cannot be attributed to a generalized response to the degeneration. 'l'hese results support the hypothesis that directed perturbation of the microenvironmental by targeted apoptosis induces a localized and specific temporal and spatial sequence of signals necessary to achieve repopulation by pyramidal neurons, and that these signals can provide an additional level of hierarchical control over immature neural precursors.

Several factors could contribute to the changes we observe following transplantation into these selectively perturbed host environments. The directed migration could potentially be supported by reemergence of structural elements such as radial glia that usually transform into astrocytes when neuronal migration is complete (Rosen et al., 1992; Sherman et al., 1992; IIatton and Hoi, 1993; Hunter and Hatten, 1993; Hernit-Grant and Macklis, 1994), or it could be due to guidance provided by the extracellular matrix or diffusible tropic factors (Politis and Miller, 1985; Stewart and Pearlman, 1987; Chun and Shatz, 1988; Liesi and Silver, 1989; Joosten et al., 1994). The appropriate differentiation could result from the altered expression of a variety of neurotrophins and growth factors, in addition to local alterations in synaptic activity (Gardette et al,, 1991; Hickmott and Constantine-Paton, 1993; Kalb and Agostini, 1993; Lohof et al., 1993; Allendoerfer et al., 1994). Trophic factors centrally influence long term survival and differentiation of neurons (Cheng and Mattson, 1991; Jacobson, 1991; Sieber-Blum, 1991; Zhang et al., 1993). Recent evidence demonstrates that basic fibroblast growth factor (bFGF) acts both as a mitogen and as a trophic factor (Reynolds and Weiss, 1992; Kilpatrick and Bartlett, 1993; Ray et al., 1993; Kitchens et al., 1994), and that it contributes to the regenerative response seen in retina and optic tract following phototoxicity or retinal dystrophy (Kostyk et al., 1994) and following traumatic cortical injury (Finkelstein et al., 1988; I iu and Chen, 1994). Similarly, expression of neurotrophins such as NGF or brain-derived neurotrophic factor (BDNF), and neurotrophin-induced receptor tryrosine kinase (Trk) phosphorylation, correlate temporally with developmental periods of neuronal migration and early differentiation (Zafra et al., 1990; Komuro and Rakic, 1993; Knusel et al., 1994). Brainderived neurotrophic factor, in particular, is implicated in normal cortical ncuron survival and differentiation, and expression increases following subtle injury due to hypoxia or excitotoxicity, but only in regions where cells remain partially viable and not necrotic (Ballarin et al., 1991; Comelli et al., 1992; Ghosh et al., 1994). Determination of the temporal and spatial expression of pivotal regulatory factors, and their roles within regions of photolytic apoptosis, will elucidate the mechanisms that drive 
cellular migration and differentiation during normal corticogenesis.

In conclusion, these studies show that selective neuronal degeneration following targeted photolysis induces a specific sequence of events that guide migration and differentiation of transplanted embryonic neurons, potentially recapitulating signaling sequences seen during development, and leading to the restoration of elements of normal cortical cytoarchitecture. Neuronal migration extends over a 2 week period following transplantation, with donor neurons assuming characteristic pyramidal phenotype in these neuron-deficient regions. This response can occur in fully adult mice, further suggesting that the potential to guide cellular migration and differentiation through alteration of microenvironmental cues remains possible despite host ages well beyond normal development. It will be of interest to investigate the cellular and molecular alterations in the regions of targeted neuronal cell death against a background in control adult cortex in which most developmentally regulated molecules will have been downregulated. Controlled perturbations of this system and these signals may allow definition of spatial and temporal patterns of developmental molecules permissive or required for directed neuronal migration and differentiation within neocortex.

\section{References}

Allendoerfer K, Cabelli R, Escandon E, Kaplan D, Nikolics K, Shatz C (1994) Regulation of neurotrophin receptors during maturation of the mammalian visual system. J Neurosci 14:1795-1811.

Angevine J, Sidman R (1961) Autoradiographic study of cell migration during histogenesis of cerebral cortex in mouse. Nature 192:766-768.

Austin C, Cepko C (1990) Cellular migration patterns in the developing mouse cerebral cortex. Development 110:713-732.

Ballarin M, Ernfors P, Lindefors N, Persson H (1991) Hippocampal damage and kainic acid injection induce a rapid increase in mRNA for BDNF and NGF in rat brain. Exp Neurol 114:35-43.

Bayer SA, Altman J (1991) Neocortical morphogenesis and histogenesis. In: Neocortical development, pp 11-29. New York: Raven.

Braisted JE, Raymond PA (1992) Regeneration of dopaminergic neurons in goldfish retina. Development 114:913-919.

Braisted JE, Raymond PA (1993) Continued search for the cellular signals that regulate regeneration of dopaminergic neurons in the gold fish retina. Dev Brain Res 76:221-232.

Braisted JE, Essman TГ, Raymond PA (1993) Regeneration of photoreceptors in goldfish retina following laser lesions. Soc Neurosci Abstr 534.2.

Cenci MA, Nilsson OG, Kalen P, Bjorklund A (1993) Characterization of in vivo noradrenaline release from superior cervical ganglia or fetal locus coeruleus transplanted to the subcortically deafferented hippocampus in the rat. Exp Neurol 122:73-87.

Cheng B, Mattson MP (1991) NGF and bFGF protect rat hippocampal and human cortical neurons against hypoglycemic damage by stabilizing calcium homeostasis. Neuron 7:1031-1041.

Chun JJ, Shatz CJ (1988) A fibronectin-like molecule is present in the developingg cat cerebral cortex and is correlated with subplate neurons. J Cell Biol 106:875-872.

Comelli MC, Seren MS, Guidolin D, Manev RM, Favaron M, Rimland JM, Canella R, Negro A, Manev II (1992) Photochemical stroke and BDNF mRNA expression. Neuroreport 3:473-476.

Ferrari B, Batistatou A, Greene LA (1993) Gangliosides rescue neuronal cells from death after trophic factor deprivation. J Neurosci 13 : 1879-1887.

Finkelstein SP, Apostolides PJ, Caday CG, Prosser J, Philips MF, Klagsbrun $M$ (1988) Increased basic fibroblast growth factor (bFGF) immunoreactivity at the site of focal brain wounds. Brain Res 460:253259

Fishell G (1993) Striatal precursors transplanted into the cortical ventricular zone generates neurons with cortical phenotype. Soc Neurosci Abstr 256.5 .

Fishman RB, Hatten ME (1993) Multiple receptor systems promote CNS neural migration. J Neurosci 13:3485-3495.
Gao W, Heintz N, Hatten ME (1991) Cerebellar granule cell neurogenesis is regulated by cell-cell interactions in vitro. Neuron 6:705715.

Gardette R, Alvarado-Mallart RM, Crepel F, Sotelo C (1988) Electrophysiological demonstration of synaptic integration of transplanted Purkinje cells into the cerebellum of the adult Purkinje cell degeneration mutant mouse. J Neurosci 24:777-789.

Gardette R, Listerud MD, Brussaard AB, Role LW (1991) Developmental changes in transmitter sensitivity and synaptic transmission in embryonic chicken sympathetic neurons innervated in vitro. Dev Biol 147:83-95.

Ghosh A, Antonini A, McConnell SK, Shatz CJ (1990) Requirement for subplate neurons in the formation of thalamocortical connections. Nature 347:179-181.

Ghosh $\Lambda$, Carnahan J, Greenberg ME (1994) Requirement for BDNF in activity-dependent survival of cortical neurons. Science 263:1618 1623.

Goodman CS, Shatz CJ (1993) Developmental mechanisms that generate precise patterns of neuronal connectivity. Cell Suppl 77-98.

Groves AK, Barnett SC, Franklin RJ, Crang AJ, Mayer M, Blakemore WF, Noble M (1993) Repair of demyelinated lesions by transplantation of purified 0-2A progenitor cells. Nature 362:414-415.

Hatton JD, Hoi SU (1993) In vitro differentiation inhibits the migration of cultured neonatal rat cortical astrocytes transplanted to the neonatal rat cerebrum. Int J Dev Neurosci 11:583-594.

Hernit-Grant C, Macklis JD (1994) Re-expression of radial glial cell marker, $\mathrm{RC} 2$, in young adult mouse cortex following targeted neuronal death. Soc Neurosci Abstr 682.6

Hickmott PW, Constantine-Paton M (1993) The contributions of NMDA, non-NMDA, and GABA receptors to postsynaptic responses in neurons of the optic tectum. J Neurosci 13:4339-4353.

Hunter KE, Hatten ME (1995) Radial glial cell transformation to astrocytes is bidirectional: regulation by a diffusible factor in embryonic forebrain. Proc Natl Acad Sci USA 92:2061-2065.

Hynes MA, Buck LB, Gitt M, Barondes S, Dodd J, Jessell TM (1989) Carbohydrate recognition in neuronal development: structure and expression of surface oligosaccharides and beta-galactoside-binding lectins. Ciba Found Symp 145:189-210.

Hynes RO, Patel R, Miller RH (1986) Migration of neuroblasts along preexisting neuronal axonal tracts during prenatal cerebellar development. J Neurosci 6:867-876.

Itakura $\mathrm{T}$, Yokote $\mathrm{H}$, Yukawa $\mathrm{S}$, Nakai M, Komai N, Umemoto $\mathrm{M}$ (1990) Transplantation of peripheral cholinergic neurons into Alzheimer model rat brain. Stereotactic Funct Neurosurg 54-55:368-372.

Jacobson M (1991) Neuronal death and neurotrophic factors. In: Developmental neurobiology, pp 311-358. New York: Plenum.

Joosten EA, Gispen WH, Bar PR (1994) Tropism and corticospinal target selection in the rat. Neuroscience 59:33-41.

Kalb RG, Agostini J (1993) Molecular evidence for nitric oxide-mediated motor neuron development. Neuroscience 57:1-8.

Kilpatrick TJ, Bartlett PF (1993) Cloning and growth of multipotential neural precursors: requirements for proliferation and differentiation. Neuron 10:255-265.

Kitchens DL, Snyder EY, Gottlieb DI (1994) FGF and EGF are mitogens for immortalized neural progenitors. J Neurobiol 25:797-807.

Knusel B, Rabin S, Hefti F, Kaplan D (1994) Regulated neurotrophin receptor responsiveness during neuronal migration and early differentiation. J Neurosci 14:1542-1554.

Komuro H, Rakic P (1993) Modulation of neuronal migration by NMDA receptors. Science 260:95-97.

Kostyk S, D'Amore P, Herman I, Wagner J (1994) Optic nerve injury alters basic fibroblast growth factor localization in the retina and optic tract. J Neurosci 14:1441-1449.

Liesi P, Silver J (1988) Is astrocyte laminin involved in axon guidance in the mammalian CNS? Dev Biol 130:774-785.

Liu HM, Chen HH (1994) Correlation between fibroblast growth factor expression and cell proliferation in experimental brain infarct: studied with proliferating cell nuclear antigen immunohistochemistry. J Neuropathol Exp Neurol 53:118-126.

Lohof AM, Ip NY, Poo MM (1993) Potentiation of developing neuromuscular synapses by the neurotrophins NT-3 and BDNF. Nature $363: 350-353$.

Macklis ID (1993) Transplanted neocortical neurons migrate selectively into regions of neuronal degeneration produced by chromphoretargeted laser photolysis. J Neurosci 13:3848-3863. 
Macklis JD, Madison R (1985) Unfocused laser illumination kills dyetargeted mouse neurons by selective photothermolysis. Brain Res 359:158-165.

Macklis JD, Madison R (1991) Neuroblastoma grafts are noninvasively removed within mouse neocortex by selective laser activation of intracellular photolytic chromophore. J Neurosci 11:2055-2062.

Macklis JD, Quattrochi JJ (1991) Restricted diffusion and stability of carbachol-fluorescent nanospheres in vivo. Neuroreport 2:247-250.

Macklis JD, Sheen VL (1992) Transplanted embryonic neocortical neurons undergo increased differentiation in selectively neuron-deficient cortex of adolescent mice. Soc Neurosci Abstr 18:932.

Macklis JD, Yoon CH, Snyder EY (1994) Immortalized neural progenitors differentiate toward repletion of a neuronal population selectively eliminated from adult mouse neocortex by targeted photolysis. Exp Neurol 129:9.

Madison R, Macklis JD (1993) Noninvasively induced degeneration of neocortical pyramidal neurons in vivo: selective targeting by laser activation of retrogradely transported photolytic chromophorc. Exp Neurol 121:153-159.

Madison R, Macklis JD, Frosch MP (1988) Noninvasive laser microsurgery selectively damages labeled mouse neurons: dependence on incident laser dose and absorption. Brain Res 445:101-110.

Madison R, Macklis JD, Thies C (1990) Latex nanosphere delivery system (LNDS): novel nanometer-sized carriers of fluorescent dyes and active agents selectively target neuronal subpopulations via uptake and retrograde transport. Brain Res 522:90-98.

Nadler JV, Evenson DA (1983) Use of excitatory amino acids to make axon-sparing lesions of hypothalamus. Methods Enzymol 103:393-. 400.

Politis MJ, Miller JE (1985) The roles of reactive gliosis and mitosis on tropic factor production in traumatized nervous system tissue. Brain Res 346:186-189

Ray J, Peterson DA, Schinstine M, Gage FH (1993) Proliferation, differentiation and long-term culture of primary hippocampal neurons. Proc Natl Acad Sci USA 90:3602-3606.

Renfranz P, Cunningham M, McKay RDG (1991) Region-specific differentiation of the hippocampal stem cell line HiB5 upon implantation into the developing mammalian brain. Cell 66:713-729.

Reynolds BA, Weiss S (1992) Generation of neurons and astrocytes from isolated cells of the adult mammaliam central nervous system. Science 255:1707-1710.

Rosen GD, Press DM, Sherman GF, Galaburda AM (1992) The development of induced cerebrocortical microgyria in the rat. J Neuropathol Exp Neurol 51:601-611.

Sheen VL, Dreyer EB, Macklis JD (1992) Calcium-mediated neuronal degeneration following singlet oxygen production. Neuroreport 3:705-708

Sheen VL, Macklis JD (1994) Apoptotic mechanisms in targeted neuronal cell death by chromophore-activated photolysis. Exp Neurol 130:67-81

Sheen VL, Cunningham MG, Hernit-Grant CS, McKay RDG, Macklis
JD (1993) Hippocampal derived, immortalized stem cell (HiB5) undergo morphologic differentiation in adult murine striatum. Soc Neurosci Abstr 19:613.

Sherman GF, Rosen GD, Stone LV, Press DM, Galaburda AM (1992) The organization of radial glial fibers in spontaneous neocortical ectopias of newborn New Zealand black mice. Dev Brain Res 67:279283.

Sieber-Blum M (1991) Role of neurotrophic factors BDNF and NGF in the commitment of pleuripotent neural crest cells. Neuron 6:949955.

Snyder EY, Deitcher DL, Walsh C, Arnold-Aldea S, Harwieg EA, Cepko CL (1992) Multipotent neural cell lines can engraft and participate in development of mouse cerebellum. Cell 68:33-51.

Snyder EY, Yandava BD, Pan ZH, Yoon CH, Macklis JD (1993) Multipotent neural progenitor cell lines can engraft and participate in development of multiple structures at multiple stages along mouse neuraxis. Soc Neurosci Abstr 256.3.

Sotelo C., Alavarado-Mallart RM (1986) Growth and differentiation of cerebellar suspensions transplanted into the adult cerebellum of heredodegeneration ataxia. Proc Natl Acad Sci USA 83:1135-1139.

Sotelo C, Alvarado Mallart RM (1987) Embryonic and adult neurons interact to allow Purkinje cell replacement in mutant cerebellum. Nature 327:421-423.

Sotelo C, Alvarado-Mallart RM (1987) Reconstruction of the defective cerebellar circuitry in adult Purkinje cell degeneration mutant mice by Purkinje cell replacement through transplantation of solid embryonic implants. J Neurosci 20: $1-22$.

Sotelo C, Alvarado-Mallart RM (1988) Integration of grafted Purkinje cell into the host cerebellar circuitry in Purkinje cell degeneration mutant mouse. Prog Brain Res 78:141-154.

Sotelo C, Alvarado-Mallart RM, Frain M, Vernet M (1994) Molecular plasticity of adult bergman fibers is associated with radial migration of grafted Purkinje cells. J Neurosci 14:124-133.

Stewart GR, Pearlman AL (1987) Fibronectin-like immunoreactivity in the developing cerebral cortex. J Neurosci 10:3325-3333.

Stromberg I, Bygedeman M, Almqvist P (1992) Target-specific outgrowth from human mesencephalic tissue grafted to cortex of ventricle of immunosuppressed rats. J Comp Neurol 315:445-456.

Takeuchi Y, Sawada T, Blunt S, Jenner P, Marsden CD (1992) Transplantation of embryonic mesencephalic and medullary raphe neurons to the neostriatum of rats with unilateral 6-hydroxydopanine lesions. Brain Res 592:129-134.

Vicario C, Cunningham MG, McKay RDG (1993) Fate shifting of cerebellar precursor cells upon transplantation into the developing dentate gyrus. Soc Neurosci Abstr 623.12.

Zafra F, Hengerer B, Leibrock J, Thoenen H, Lindholm D (1990) Activity dependent regulation of BDNF and NGF mRNAs in the rat hippocampus is mediated by non-NMDA glutamate receptors. EMBO J 9:3545-3550.

Zhang Y, Tatsuno T, Carney JM, Mattson MP (1993) Basic FGF, NGF, and IGFs protect hippocampal and cortical neurons against iron-induced degeneration. J Cereb Blood Flow Metab 13:378-438. 